\title{
Uncertainty Analysis
}

\author{
Technical Report
}

\author{
March 1982
}

Ralph E. Thomas

\section{Battelle Columbus Laboratories $505 \mathrm{King}$ Avenue \\ Columbus, $\mathrm{OH} 43201$}

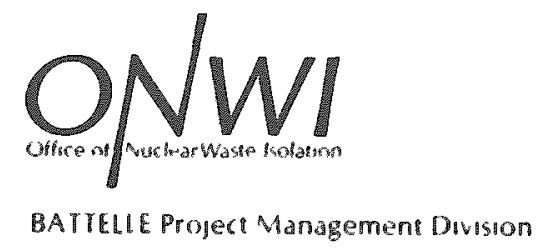




\section{DISCLAIMER}

This report was prepared as an account of work sponsored by an agency of the United States Government. Neither the United States Government nor any agency Thereof, nor any of their employees, makes any warranty, express or implied, or assumes any legal liability or responsibility for the accuracy, completeness, or usefulness of any information, apparatus, product, or process disclosed, or represents that its use would not infringe privately owned rights. Reference herein to any specific commercial product, process, or service by trade name, trademark, manufacturer, or otherwise does not necessarily constitute or imply its endorsement, recommendation, or favoring by the United States Government or any agency thereof. The views and opinions of authors expressed herein do not necessarily state or reflect those of the United States Government or any agency thereof. 


\section{DISCLAIMER}

Portions of this document may be illegible in electronic image products. Images are produced from the best available original document. 


\title{
BIBLIOGRAPHIC DATA
}

Thomas, R. E., 1982. Uncertainty Analysis, ONWI-380, prepared by Battelle Columbus Laboratories for Office of Nuclear Waste Isolation, Battelle Memorial Institute, Columbus, $\mathrm{OH}$.

\begin{abstract}
NOTICE
This report was prepared as an account of work sponsored by an agency of the United States Government. Neither the United States Government nor any agency thereof, nor any of their employees, makes any warranty, express or implied, or assumes any legal liability or responsibility for the accuracy, completeness, or usefulness of any information, apparatus, product, or process disclosed, or represents that its use would not infringe privately owned rights. Reference herein to any specific commercial product, process, or service by trade name, trademark, manufacturer, or otherwise, does not necessarily constitute or imply its endorsement, recommendation, or favoring by the United States Government or any agency thereof. The views and opinions of authors expressed herein do not necessarily state or reflect those of the United States Government or any agency thereof.
\end{abstract}

Printed in the United States of America

Available from

National Technical Information Service

U.S. Department of Commerce

5285 Port Royal Road

Springfield, VA 22161

NTIS price codes

Printed Copy: A04

Microfiche copy: A01 


\title{
Uncertainty Analysis
}

\author{
ONIJI -380
}

DE82 020058

\author{
Technical Report
}

\section{March 1982}

\author{
Ralph E. Thomas
}

\section{Battelle Columbus Laboratories 505 King Avenue Columbus, OH 43201}

This report was prepared by Battelle Columbus Laboratories under Subcontract E516-04100 with Battelle Project Management Division, Office of Nuclear Waste Isolation under Contract No. DE-AC06-76RLO1830-ONWI with the U.S. Department of Energy. This contract was administered by the Battelle Office of Nuclear Waste Isolation. 
An evaluation is made of the suitability of analytical and statistical sampling methods for making uncertainty analyses. The adjoint method is found to be well-suited for obtaining sensitivity coefficients for computer programs involving large numbers of equations and input parameters. For this purpose the Latin Hypercube Sampling method is found to be inferior to conventional experimental designs. The Latin hypercube method can be used to estimate output probability density functions, but requires supplementary rank transformations followed by stepwise regression to obtain uncertainty information on individual input parameters. A simple cork and Bottle problem is used to illustrate the efficiency of the adjoint method relative to certain statistical sampling methods. For linear models of the form $A \underline{x}=\underline{b}$ it is shown that a complete adjoint sensitivity analysis can be made without formulating and solving the adjoint problem. This can be done either by using a special type of statistical sampling or by reformulating the primal problem and using suitable linear programming software. 
$\therefore$ 


\section{EXECUTIVE SUMMARY}

\section{INTRODUCTION}

ONWI is currently developing an integrated set of first-order models for the NWTS program. Using these models ONWI wishes to perform uncertainty analyses of the performance of the isolation system. From these analyses, ONWI intends to define the uncertainty in the performance predictions at various levels of confidence and determine the models and model parameters that make the greatest contributions to that uncertainty.

OBJECTIVE

This task involves a review of the literature, reports, and other documents related to techniques for making uncertainty analyses. Uncertainty analysis is concerned with the effects of variations in the magnitudes of input parameters, called input uncertainties, on the variations of computed outputs, called output uncertainties. Some computed outputs are relatively sensitive to small changes in some input values, and are relatively insensitive to changes in other input values. For large computer simulations, based on many mathematical equations and hundreds of input parameters, the sensitivities of computed outputs to changes in individual inputs, or combinations of inputs, are not readily apparent. Some techniques for making uncertainty analyses make direct use of the mathematical equations that are represented and solved by the computer code. These techniques are called analytical and are wellrepresented by a technique known as the adjoint method of sensitivity analysis. Other techniques for making uncertainty analyses treat the computer code as a "black box". With these techniques the input parameters are perturbed according to certain patterns. The computer program is then re-run for each pattern in order to determine the sensitivity of computed outputs to changes in inputs. The perturbed input patterns are frequently selected in accord with statistical concepts associated with the design of experiments. For this reason such techniques for making uncertainty analyses are called statistical sampling techniques, and are represented by a method known as Latin hypercube sampling. 
The objective of this task is to compare the analytical and statistical sampling techniques for making uncertainty analyses.

PROCEDURES

The task was accomplished by reviewing published literature, reports, computer codes, and other documents related to techniques for making uncertainty analyses. Frequent discussions and small workshops were held with the Technical Monitor and Technical Administrator as the effort progressed. Conference calls were made with several experts to obtain clarifying information.

A simple example, called the Cork and Bottle problem, was developed to illustrate the strengths and weaknesses of the analytical and statistical sampling methods.

\section{RESULTS}

The analytical methods are found to be superior to the statistical sampling methods in logical rigor and numerical accuracy. This finding stems primarily from the fact that analytical methods make direct use of the mathematical equations that are represented by the computer code. Among the analytical methods, the adjoint method is found to be particularly well-suited for obtaining the sensitivity coefficients for all input parameters, taken individually or in combination. With proper attention to coding procedures and with the use of currently developing software for obtaining partial derivatives (GRESS), the incremental costs for formulating and solving the adjoint version of the computer code can be minimized.

Among the statistical sampling methods, the Latin hypercube technique is found to be based on procedures that are generally unacceptable to classically trained statisticians. This stems directly from the use of random procedures to determine which combinations of perturbed inputs should be run using the computer code. With the use of Latin hypercube sampling it is necessary to make rank transformations of the data, followed by stepwise regression, in order to obtain questionable sensitivity 
information on individual input parameters. Latin hypercube sampling is based on a sampling method that does not control the type or extent of confounding among main effects and interactions. As a result, the sampling is inferior to conventional experimental designs, such as fractional factorials and main-effect designs. The primary virtue of Latin hypercube sampling is the fact that it yields unbiased estimates of the probability density functions for computer outputs.

The adjoint method of sensitivity analysis is not well known outside of the field of nuclear engineering. Simple expository examples of the method were not found in the literature. Some practitioners suggested that the simplest examples of the adjoint method are represented by eigenvalue problems or by sets of simultaneous differential equations. At the risk of oversimplification, a simple Cork and Bottle problem was developed on this task for expository purposes. The problem is found to provide simple illustrations of several of the principal features of the adjoint method. The problem also serves to provide a basis for comparing techniques of sensitivity analysis based on statistical sampling with those of the adjoint method.

Because of the linearity of the Cork and Bottle problem, several interesting and possibly useful results were obtained. A generalized Cork and Bottle problem consists of a set of $n$ simultaneous linear equations in $n$ unknowns, denoted by $A \underline{x}=\underline{b}$, together with a response function of the form $R=\underline{c} \cdot \underline{x}$. For such systems with $A, b$, and $c$ specified, the adjoint sensitivity equation is found to be given as follows:

$$
\frac{d R}{d \alpha}=\underline{x} \cdot \frac{\partial C}{\partial \alpha}+\underline{y} \cdot\left(\frac{\partial b}{\partial \alpha}-\frac{\partial A}{\partial \alpha} \underline{x}\right)
$$

where $\alpha$ is a generic variable that can assume the label of any of the $A$, $b$, or $c$ input parameters, and $\underline{x}$ and $\underline{y}$ respectively denote the vector solutions to the original and the adjoint version of the problem. The numerical sensitivities can be found once the numerical solutions for $\underline{x}$ and $y$ are obtained.

For the linear case it is found that a complete adjoint sensitivity analysis can be made without formulating, coding, and solving the adjoint 
version of the primal problem. This can be done in either of two ways. One method is based on a special type of statistical sampling, called adjoint-sampling in this report. The other method is based on transforming the primal problem into a linear programming problem.

In the adjoint-sampling method, $n$ additional runs of the primal program are required. The $n$ additional runs are defined by successively increasing the value of each b-parameter by unity, then re-running the program, and re-computing the value of the response function. The change in the value of the response function from its value in the original run is found to be numerically equal to the value of an adjoint variable. After $n$ additional runs the entire $y$-solution to the adjoint problem is known and the sensitivities of all input parameters can then be computed using the above equation.

The adjoint-sampling method requires a total of $(n+1)$ runs of the primal computer program. A conventional application of the adjoint method requires two runs: one run of the primal program and one run of the adjoint program. A crude cost criterion is derived in the report by comparing the cost of making $n$ additional runs of the primal program versus the cost of formulating, coding, and running the adjoint program. Under simplifying assumptions it is shown that the adjoint-sampling method is less costly than the conventional adjoint method for this linear case provided the number of equations $n$ is less than $1+\left(C_{S} / C_{R}\right)$, where $C_{S}$ denotes the cost of programming the primal problem and $C_{R}$ denotes the cost of a computer run. If the programming costs exceed the running costs by a factor of 100, for example, then the adjoint-sampling method is less costly until the number of equations in the primal problem exceeds 101.

A second method for making a complete sensitivity analysis of the linear case without solving the adjoint problem involves transforming the primal problem into a linear programming problem. The transformation is required in order to obtain an equivalent problem in which al1 input parameters are non-negative. This is a simple, standard type of transformation we11-known in linear programming. With this transformation to a linear programming problem a software package is then used that yields the solutions to both the primal and the dual versions of the 
linear programming problem. The $\underline{x}$ and $\underline{y}$ solutions of the given linear system are then obtained by a simple transformation from the primal and dual solutions given by the linear programming output. With this approach the complete adjoint sensitivity analysis can be made without formulating and solving the adjoint problem and without making additional statistical sampling runs of the computer program.

RECOMMENDATIONS

Based on the results of this task the following recommendations are made:

- ONWI should support the development and application of the adjoint method of sensitivity analysis.

- ONWI should not support the development of the Latin hypercube sampling method for sensitivity analysis. Limited use of the Latin hypercube sampling method may be justified for obtaining unbiased estimates of the probability density functions for computed outputs.

- ONWI should closely follow developments related to other analytical techniques for making sensitivity analyses.

- ONWI should rely as much as possible on conventional statistical procedures for quantifying the uncertainties of input parameters.

- ONWI should rely on conventional statistical designs, such as fractional factorials, for limited uncertainty analyses based on statistical sampling methods. External evidence should first be obtained in order to identify which main effects and interactions 
viii

among the input parameters of the program are negligibly sma11. An experimental design should then be used with confounding properties that are consistent with the identified negligible effects. 
Page

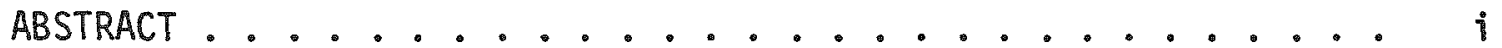

EXECUTIVE SUMMARY ....................... i i

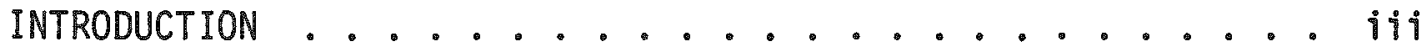

OBJECTIVE ............................

PROCEDURES ........................ iv

RESULTS .......................... iv

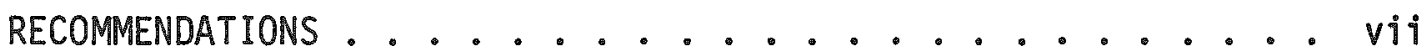

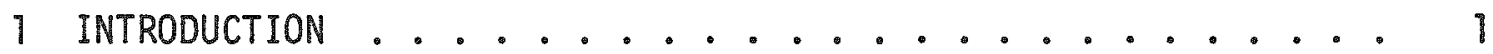

1.1 BASIC DEFINITIONS AND CONCEPTS .......... 2

1.1.1 Definition of Sensitivity ......... 3

1.1.2 Definition of Sensitivity Coefficient..... 3

1.1.3 Definition of Sensitivity Analysis ...... 4

1.1.4 Definition of Uncertainty ......... 4

1.1.5 Definition of Uncertainty Analys is ...... 4

1.2 EXTENSIONS OF CONCEPTS AND DEFINITIONS

RELATED TO UNCERTAINTY ANALYSIS ......... 4

2 THE STATISTICAL SAMPLING APPROACH TO UNCERTAINTY ANALYSIS . . 6

2.1 STATISTICAL RESPONSE SURFACES ......... 6

2.2 STATISTICAL DESIGN OF EXPERIMENTS ........ 8

2.2.1 Main Effects and Interactions ......... 9

2.2.2 Required Number of Runs .......... 10

2.2.3 Reduced Experimental Designs and Confounding ... 10

2.2.4 Assumptions and Required Numbers of Runs for Reduced Experimental Designs ....... 11

2.3 LATIN HYPERCUBE SAMPLING DESIGN .......... 12

2.3.1 Comparisons Between Latin Hypercube Designs and Conventional Experimental Designs..... 14

2.3.2 Latin Hypercube Sampling and Sensitivity

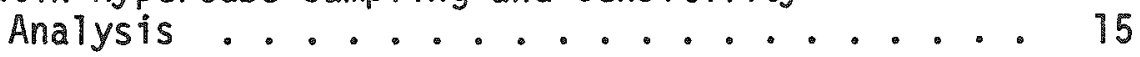


TABLE OF CONTENTS

(Continued)

Page

3 ANALYTICAL APPROACHES TO UNCERTAINTY ANALYSIS ....... 17

3.1 THE ADJOINT METHOD . . . . . . . . . . 17

3.1.1 The Total Differential ......... 18

3.1 .2 Propagation of Error ......... 19

3.1.3 Constrained Increments ......... 19

3.1.4 The Cork and Bottle Problem ......... 20

3.1.5 Generalized Cork and Bottle Problem ....... 21

3.2 PROCEDURE FOR MAKING AN ADJOINT SENSITIVITY ANALYSIS . . 24

3.2.1 Adjoint Sensitivity Equation for the Generalized Cork and Bottle Problem ..... 26

3.2.2 Complete Sensitivity Analysis for the Cork and Bottle Problem .......... 26

3.3 ADDITIONAL RESULTS FOR THE LINEAR CASE ....... 30

3.3.1 Numerical Relations Among the Sensitivity Coefficients for the Linear Case ....... 31

3.3.2 Computed Changes in Output Response ...... 31

3.3.3 Calculation of Main Effects ......... 33

3.3.4 Statistical Propagation of Uncertainty ..... 33

3.3.5 The Statistical Approach Revisited: The Adjoint-Sampling Method ....... 35

3.3.6 A Cost Criterion for the Linear Case ...... 36

3.4 LINEAR PROGRAMMING SOLUTIONS TO CORK AND BOTTLE

PROBLEMS ..................... 38

3.4.1 A Numerical Example .......... 39

4 CONCLUSIONS ....................... 45

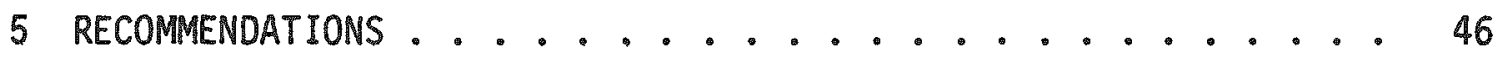

6 LIST OF REFERENCES ................... 47

\section{APPENDIXES}

APPENDIX A. ALTERNATE DERIVATION OF THE ADJOINT SENSITIVITY EQUATION ............ 
LIST OF TABLES

Page

Table 1. Procedure for Making a Sensitivity

Analysis Using the Adjoint Method

(Linear Case)

25

Table 2. Derivations of Adjoint Sensitivity

Equations . . . . . . . . . . . . . 27

Table 3. Sensitivity Coefficients for the Cork and Bottle Problem. . . . . . . . . . . . 29

Table 4. Linear Programming Solution to the Cork and Bottle Problem .............. 42 
TOPICAL REPORT

on

UNCERTAINTY ANALYSIS

to

OFFICE OF NUCLEAR WASTE ISOLATION

from

BATTELLE

Columbus Laboratories

\section{INTRODUCTION}

ONWI is in the process of developing a performance assessment capability for the National Waste Terminal Storage (NWTS) program. This capability is intended to include an integrated system of simple models which describes the behavior of the overall isolation system to a first order of approximation. The models are expected to involve hundreds of input variables and parameters and will be costly to run. Using this system of mode1s, ONWI wishes to perform uncertainty analyses of the performance of the isolation system. From these analyses, ONWI intends to define the uncertainty in the performance predictions at various levels of confidence and determine the models and model parameters which make the greatest contribution to that uncertainty.

There have been two different technical approaches (and a number of variants) proposed to ONWI about how this work might be accomplished. These technical approaches may be classified as "statistical" or "analytical" and are represented, for example, by the Latin hypercube sampling method and the adjoint method, respectively.

The choice between these approaches is important to ONWI for both cost and technical reasons. Roughly, analytical methods trade increased costs in the initial programming stage for decreased costs during subsequent stages. The statistical methods typically have lower initial costs because computer runs are made only for selected combinations of input perturbations judged to be important. However, as more detailed sensitivity 
analyses are made, the costs of making additional runs may become prohibitively large. In addition to cost differentials the two approaches also have technical differences. The technical differences stem largely from the fact that the statistical approaches treat the computer code as a "black box". The sensitivity structure of the black box is deduced by analyzing the input-output relations that are exhibited when the computer code is repeatediy run using carefully selected combinations of perturbed inputs. In contrast, the analytical methods "Took inside the black box" and make explicit use of the mathematical relations that are involved in the simulation models.

The effort reported below aims to evaluate the appropriateness and usefulness of statistical and analytical methods for application to ONWI's analyses of uncertainty.

\subsection{BASIC DEFINITIONS AND CONCEPTS}

For clarity of exposition certain terms are defined in this section. In some instances the terms are represented in symbolic form to better describe the associated concept. The aim is to be simple and suggestive, not rigorous.

Consider a response function of $n$ variables $x_{j}, \ldots, x_{n}$, and $m$ parameters $a_{1}, \ldots, a_{m}$. The function may be represented by

$$
R(\underline{x}, \underline{a})=R\left(x_{1}, \ldots, x_{n} ; a_{1}, \ldots, a_{m}\right) .
$$

It is assumed that this function can be differentiated with respect to the parameters. A Taylor's series expansion of the function at the point $\left(\underline{x}^{\circ}, \underline{a}^{\circ}\right)$ consists of terms of the following form:

$$
\frac{\partial R}{\partial \alpha^{\circ}} d \alpha
$$

where a denotes a "generic" variable that represents any parameter. As shown by the superscript the partial derivative $\partial R / \partial \alpha^{\circ}$ is considered to be evaluated at the point $\left(\underline{x}^{\circ}, \underline{a}^{\circ}\right)$. Geometrically, the numerical value 
of the partial derivative is associated with the slope of a tangent plane at this point. The factor $d \alpha$ represents a small change from the parameter value $\alpha^{\circ}$ so that

$$
d \alpha=\alpha-\alpha^{\circ}
$$

represents a perturbation of $\alpha$ from the reference value $\alpha^{\circ}$. The product of the partial derivative and the perturbation, shown in Equation (2), represents the approximate change in the function $R$ due to the change in a. The exact change in the function could be obtained by re-computing the function $R$ with $\left(\alpha^{\circ}+d \alpha\right)$ substituted for $\alpha^{\circ}$. The approximation given by $\left(a R / \partial \alpha^{\circ}\right) d \alpha$ will be a good approximation to the exact change in the value of $R$ provided da is sufficiently small.

\subsubsection{Definition of Sensitivity}

The partial derivative $\partial R / \partial \alpha^{\circ}$ is called the sensitivity of the function $R$ to a perturbation in $\alpha$ at the point $\left(x^{\circ}, a^{\circ}\right)$. Note that the sensitivity can change from point to point. Also note that for a given perturbation $d \alpha$, the resulting change in $R$ can be much larger than $d \alpha$ (if $\partial R / \partial \alpha^{\circ}$ is large) or much smaller than $d \alpha$ (if $\partial R / \partial \alpha^{\circ}$ is small).

\subsubsection{Definition of Sensitivity Coefficient}

Let $d R$ denote the change in the response function that results from the perturbation $d \alpha$. Further, let $d R / R$ denote the fractional (or percentage) change that results from the fractional (or percentage) change $d \alpha / \alpha$. The sensitivity coefficient is given by the ratio

$$
\frac{d R / R}{d \alpha / \alpha}=\frac{d(\ln R)}{d(\ln \alpha)}
$$

Note that this is a dimensionless (pure) number and represents the percentage change in output $d R / R$ relative to the percentage change in input $d \alpha / \alpha$. For example, if the sensitivity coefficient for $\alpha$ is 2 then the percentage change in the output is twice that of the input. 


\subsubsection{Definition of Sensitivity Analys is}

In this report a sensitivity analysis is taken to be an analysis that provides quantitative estimates for the sensitivity coefficients $d(7 n R) / d(7 n \alpha)$ associated with some, or a 77 , of the input $\alpha^{\prime} s$.

\subsubsection{Definition of Uncertainty}

The term "uncertainty" is broadly used in the literature to refer to a variety of different concepts. These include variations in computed outputs related to standard deviations of input parameters, to the use of "guesstimates" for input parameter values, to a lack of knowledge concerning the exact forms for the equations included in the associated mathematical models, and to a lack of knowledge concerning the models themselves. For this reason, the term uncertainty is used in this report to refer to any of these variations, with the exception that $\partial R / \partial \alpha$ is generally called a partial derivative and $d(\ln R) / d(\ln \alpha)$ is generally called a sensitivity coefficient. All other quantities, such as $\mathrm{d} \alpha_{i}, \sigma_{i}{ }^{2}$; products such as $\left(\partial R / \partial \alpha^{\circ}\right) \mathrm{d} \alpha$; sums of products such $\sum_{i=1}^{k}\left(\partial R / \partial \alpha_{i}^{\circ}\right) d \alpha_{j}$, etc., are called uncertainties.

\subsubsection{Definition of Uncertainty Analys is}

In this report an uncertainty analysis is taken to be an analysis that provides quantitative estimates for $d \alpha_{j}, d \alpha_{i} / \alpha_{i}, \sigma_{i}{ }^{2}$, or related measures of input and output variability and generaily involves an algebraic combination of these estimates with the sensitivity coefficients to yield an overall measure of uncertainty. It is noted that, under the above definitions, a sensitivity analys is is usually required as input to an uncertainty analysis.

\subsection{EXTENSIONS OF CONCEPTS AND DEFINITIONS RELATED TO UNCERTAINTY ANALYSIS}

The reader is referred to the text by Frank $(1)$ for extensions of the concepts and definitions given above. The sensitivity coefficient 
given in Equation (3) is a static special case of Frank's "relative (logarithmic) sensitivity function" which may be time (or frequency) dependent. Six other measures of uncertainty are also included in the text, together with a classification of parameter variations that include $\alpha$-variations that do not change the order of associated differential equations; $\beta$-variations that are associated with uncertainties in the initial conditions of differential equations; and $\lambda$-variations that affect the order of the differential equations. 


\section{THE STATISTICAL SAMPLING APPROACH TO UNCERTAINTY ANALYSIS}

In this section conventional concepts are reviewed that relate to the statistical sampling approach to uncertainty analysis. These concepts involve the fitting of a response surface to a pattern of discrete points that are selected in accord with an experimental design. The discussion is focused on the strengths and weaknesses of fitting response surfaces. Special attention is given to the number of points required to define a response surface. Brief references are made to factorial experiments and to the confounding of main effects and interactions that occur when such factorials are reduced to designs that require fewer runs. The primary purpose of this discussion is to provide a basis for contrasting conventional concepts of experimental designs with those associated with the Latin hypercube design.

The strategy of the statistical approach to uncertainty analysis generally consists of regarding a computer code as a "black box" which transforms input numerical values into output numerical values. Quantitative relations between inputs and outputs are identified and studied by making repeated runs of the computer code with inputs set at carefully selected incremental values taken over permissible ranges of the input values. In this sense the computer code is subjected to a set of experimental runs, with each experimental run designed to give additional information concerning the quantitative relation between the input values and the output values. With this approach statistical concepts, normally associated with the design of experiments, can be applied to analyze the "data" from the experimental runs. Standard computational procedures can then be used to fit general quantitative models that describe the approximate relation between inputs and outputs.

\subsection{STATISTICAL RESPONSE SURFACES}

The mathematical model that results from the statistical approach is geometrical1y represented by a "response surface" in an $(n+1)$ dimensional space. The surface represents the magnitude of a selected 
output over the range of values of each of the $n$ inputs. When the inputoutput relations are well-behaved the response surface is usually considered to be smooth with smoothly changing "slopes". This permits the use of mathematical models that are continuous in the inputs and have continuous partial derivatives. After the surface is fitted, the equation representing the surface can be mathematically analyzed to estimate slopes, determine approximate locations of maxima, determine contours, etc.

It is important to note that the response surface is computed only at a finite number of selected combinations of discrete values of the inputs. Thus, the output points of the response surface represent a discrete point-approximation to the "true" continuous surface. Even if the response surface is required to pass exactly through each discrete output point, there is no guarantee that the fitted response surface will correctly represent the output magnitudes for interpolated or extrapolated values of the inputs. In fact, it is usually considered to be undesirable to fit a polynomial response surface exactly to a discrete set of output points because the behavior of a polynomial surface between the fitted points is frequently unacceptable. To avoid overfitting and underfitting it is usually necessary to fit a variety of polynomial surfaces with differing polynomial degrees for different input variables. That is, the output may be linear in some inputs, but in other inputs the output may be better represented by quadratic, cubic, or higher degree polynomials.

The primary technique for fitting response surfaces involves the use of a polynomial regression analysis. Efficient computer software makes it possible to fit a variety of regression models, having widely different structures, in an effort to identify a suitable regression mode1. Although this approach is feasible and widely used, it must be noted that considerable judgment on the part of the analyst must be exercised. Judgment is required, for example, in the selection of the mathematical structure of possible regression models, in choosing proper criteria for identifying a suitable fit at the computed points, in choosing criteria for acceptable behavior between computed points, in selection of techniques for validating the fitted model, etc. 
Judgment is also required in the selection of the experimental design that is used to obtain the computed points required to define the response surface. How many computer runs need to be made? How many "levels" of each input parameter should be used in the experimental design? How will the resulting data be analyzed? Will the analysis identify which input parameters are most important in determining the output? Although there is general agreement that these kinds of questions should be asked, there is frequent disagreement in the answers to these kinds of questions, even among professional statisticians. In the following paragraphs the question of the experimental design used to select the input values is considered in more detail.

\subsection{STATISTICAL DESIGN OF EXPERIMENTS}

The statistical design of experiments can be illustrated by a simple example. Suppose that a computed numerical output, called a response $R$, depends on two numerical inputs, say $\alpha_{1}$ and $\alpha_{2}$. This dependence is symbolized by writing

$$
R=R\left(\alpha_{1}, \alpha_{2}\right)
$$

Let $\alpha^{\circ}$ denote a specified value of an input parameter, and let $R^{\circ}$ denote the resulting response, so that

$$
R^{\circ}=R\left(\alpha_{1}^{\circ}, \alpha_{2}^{\circ}\right)
$$

Depending on the model and the data used in the calculations, the specified values of the $\alpha^{\prime}$ s may be nominal values fixed by system design considerations, reference values obtained from the study of an experimental prototype model, estimated values (least-squares, maximum likelihood) obtained from fitting a mathematical model to measurement data, measures of location (means, medians, or modes) associated with probability density functions for the a's, "guesstimates" based on expert opinion, etc. The term "nominal value" is used for all of these possibilities in the remainder of this report. 
The uncertainty in the correct value for $\alpha$ is frequently represented by an increment $d \alpha=\alpha-\alpha^{\circ}$, and by a fractional (or percentage) change $d \alpha / \alpha=\left(\alpha-\alpha^{\circ}\right) / \alpha$. Thus, the uncertainty in $\alpha$ is measured in terms of a possible deviation of $\alpha$ from its nominal value $\alpha^{\circ}$.

For the above example, suppose that $\pm \mathrm{d}_{1}$, and $\pm \mathrm{d} \alpha_{2}$ represent the uncertainties in $\alpha_{1}$ and $\alpha_{2}$, respectively. These uncertainties give rise to 9 combinations of levels of input values that could be run using the computer code. Specifically, with $\alpha_{1}$ set at its low level, coded $(-1)$, three runs would be made with $\alpha_{2}$ set at a low level $(-1)$, nominal level $(0)$, and high level (1). These three runs can be symbolized by $\left(\alpha_{1}, \alpha_{2}\right)=$ $(-1,-1),,(-1,0)$, and $(-1,1)$. Similarly, the three levels for $\alpha_{2}$ could be run in combination with $\alpha_{1}$ at level $(0)$ to give $(0,-1),(0,0)$, and $(0,1)$, and with $\alpha_{1}$ at $i$ ts high level to give $(1,-1),(1,0),(1,1)$. The resulting combinations give 9 points on the response surface. The experimental design associated with these 9 points is called a complete factorial. In general, with $m$ input parameters and 3 levels for each parameter, the number of runs required for a complete factorial design is given by $3^{m}$. For even a moderate number of input parameters, say 8 , it is found that $3^{8}$ or 6,567 runs would be required to (partialiy) define the response surface using a complete factorial design. For computer codes which are costly to run and have hundreds of input parameters, it is clear that the complete factorial design cannot be used.

\subsubsection{Main Effects and Interactions}

A rather thorough analysis can be made of the data obtained when a complete factorial design is used. The results of such analyses are usually expressed in terms of "main effects" and "interactions". Roughiy, the unconditional main effect of an input is measured in terms of the difference between the average response over all runs made, with the input set at a high level, minus the average response over all runs made, with the input set at a low level. Two conditional main effects of $\alpha_{1}$ can also be computed. The main effect of $\alpha_{1}$ can be computed under the condition that $\alpha_{2}$ is at a high level, and under the condition that $\alpha_{2}$ is at a low level. If these two conditional main effects differ 
appreciably, then $\alpha_{1}$ and $\alpha_{2}$ are said to interact; that is, the average effect on the response of changing $\alpha_{1}$ depends on the level of $\alpha_{2}$. Similar interpretations of interactions are possible and are useful for combinations of more than 2 inputs.

\subsubsection{Required Number of Runs}

It should be noted that the number of levels for each input serves as a measure of the polynomial degree that can be associated with the fitted response surface. With 2 levels for each parameter, only linear main effects and linear-by-linear interactions can be identified and quantified. The use of 3 levels permits quadratic effects to be analyzed, and in general, the use of $(K+1)$ levels permits the $k$ th degree polynomial effects to be treated. The number of required runs for the complete factorial for $m$ inputs, with $(K+1)$ levels per input, is given by $(K+1)^{m}$. This usually yields a number of runs for a complete factorial that is unacceptably large. Yet, in terms of the polynomial structure of the associated response surface, it is often conceptualiy oversimple. For example, the 6,561 runs for the $3^{8}$ complete factorial considered above can only account for quadratic effects.

\subsubsection{Reduced Experimental Designs and Confounding}

Many different experimental designs have been devised in order to reduce the number of runs below that required by the complete factorial. However, each reduction in the number of runs entails a loss of information on the main effects and interactions. That is, for the reduced designs the main effects and interactions of some of the inputs cannot be estimated from the resulting data because of "confounding". Confounding occurs when two different estimation formulas based on the complete facotrial become identical because of the fact that certain runs were not made. Thus, with the data available from the reduced design the one effect cannot be distinguished from the other. In such cases, it is common practice to use whatever knowledge there may be about the system that would indicate, in advance, which main effects and interactions can 
be correctly assumed to be negligible. Suppose that in a particular design the main effect of $\alpha_{1}$ is confounded with the interaction effect, $\alpha_{7} \mathrm{X}_{2}$. Suppose, in addition, that it can correctly be assumed that the interaction effect is zero. It follows that the reduced formula for computing either the main effect of $\alpha_{1}$ or the interaction effect $\alpha_{7} x_{2}$ will, under this assumption, give an estimate of the main effect of $\alpha_{7}$.

It is clear that the correct use of reduced experimental designs depends on the validity of the assumption that certain specified main effects and interactions are zero. In general, the correctness of these assumptions depends on external supplementary information. To test the correctness of the assumptions using data from the computer runs it would be necessary to make certain runs that were formerly excluded from the design.

Based on this discussion it is clear that a reduction in the number of runs below that associated with a complete factorial design requires external knowledge of certain structural relations between the inputs and outputs of the computer code. In strict terms, the computer code can no longer be considered to be a "black box". Certain input-output relations must be assumed. Examples of the kinds of assumptions required are considered next.

\subsubsection{Assumptions and Required Numbers of \\ Runs for Reduced Experimental Designs}

In Reference (2) a reduced design of 243 runs is given for a case involving 10 inputs with 3 levels each. This is a 1/243 reduction from the $3^{10}=59,049$ runs that would be required by a complete factorial design. With this design the 10 main effects and 45 two-factor interactions can be estimated; 58,993 higher order effects cannot be estimated. On this basis it follows that the correct use of this design requires external evidence for the validity of 58,993 assumptions.

Another example from Reference (3) involves 16 factors at 2 levels each for a total of 256 required runs out of a total of 65,536 runs for the complete factorial. A11 16 main effects and 114 out of 120 twofactor interactions can be estimated from the resulting data. Note that in order to use this design external knowledge would be required to 
indicate that exactly 6 two-factor interactions are zero and that all other higher order interactions are zero.

A class of $2^{k}$ experimental designs, called resolution III, permit the estimation of main effects only, under the assumption that all higher order interactions are zero. In general, these designs permit the main effects of $2^{k}-1$ inputs to be estimated using $2^{k}$ runs. For example, 15 main effects can be estimated using data from 16 runs; 127 main effects using 128 runs, etc. Similar designs, known as Plackett and Burman designs, are also available when the number of runs that can be made is a multiple of $4 .{ }^{(4)}$ These designs require the minimum number of runs and the strongest assumptions.

\subsection{LATIN HYPERCUBE SAMPLING DESIGN}

The Latin hypercube sampling (LHS) design has been advanced as an appropriate technique for selecting the levels of input parameters to be run using computer codes involving hundreds of variables when the outputs are monotone functions of the intputs. The resulting data are first analyzed to obtain estimates of the means, variances, and distribution functions of the outputs. A subsequent analys is is then based on a transformation using ranks and is followed by applying stepwise regression. These latter analyses are aimed at determining which input variables have the most effect in determining the magnitudes of the outputs. A considerable amount of theoretical development and some illustrative applications of the approach have been reported. (5)

The following simple two input example of LHS is based on that given in Reference (6). Let the range of $\alpha_{1}$ and $\alpha_{2}$ be divided into 4 non overlapping intervals associated with equal probabilities. The intervals are shown in the following sketch.

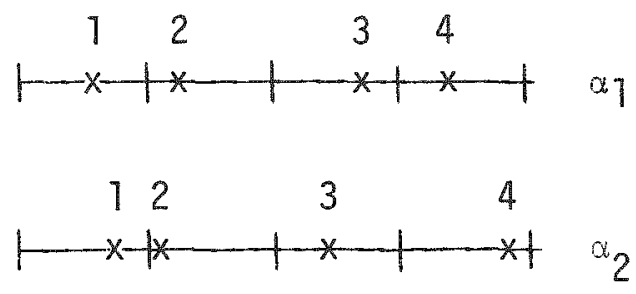


Randomly selected values of $\alpha_{1}$ and $\alpha_{2}$ are obtained within each interval as suggested by the $x^{\prime} s$ labeled $(1,2,3,4)$ in the above sketch. Finally, suppose that the labels for $\alpha_{1}$ are permuted at random and give ${ }_{7}:(3,1,2,4)$, and that an independent random permutation is applied to the labels for $a_{2}$ to give $\alpha_{2}:(4,1,3,2)$. These permutations may be displayed as a matrix of 2 a-rows and 4 columns:

\begin{tabular}{|c|c|c|c|c|}
\hline \multirow[b]{2}{*}{ Input } & \multicolumn{4}{|c|}{ Run } \\
\hline & 1 & 2 & 3 & 4 \\
\hline$\alpha_{1}$ & 3 & 1 & 2 & 4 \\
\hline$a_{2}$ & 4 & 1 & 3 & 2 \\
\hline
\end{tabular}

The LHS design then consists of making 4 computer runs using the $\left(\alpha_{1}, \alpha_{2}\right)$-levels corresponding to the 4 columns of this matrix: $\left(\alpha_{1}, \alpha_{2}\right)=(3,4),(1,1)$, $(2,3),(4,2)$ for runs $1,2,3,4$, respectively.

In a more general setting it is seen that the LHS design is obtained as follows:

(1) Partition the range of each input variable $u_{i}, i=1, \ldots, m$ into $N$ equiprobable intervals, where $N$ denotes the number of runs to be made.

(2) Sample at random within each subinterval to determine $N$ levels for $\alpha_{1}$ and label the levels $1,2, \ldots, N$; repeat the procedure for each remaining input $\alpha$.

(3) Randomly and independently permute the Tabels for each input $\alpha$, and form a design matrix of the resulting rows.

(4) Make $N$ runs of the computer code using the $\alpha$-levels corresponding to those given by successive columns of the design matrix. 
2.3.1 Comparisons Between Latin

Hypercube Designs and Conventional

Experimental Designs

An application of the LHS design is given in Reference (5). The application involves $N=200$ runs and 7 input variables. Thus, for a given input, each interval represents a probability of $1 / 200=$ 0.005 . The resulting design matrix defining the computer runs consists of 7 rows, corresponding to the input variables, and 200 columns, corresponding to the 200 runs. The application was repeated using $N=1000$ runs with very little change obtained in the cumulative distribution function of the output.

At this point it is convenient to contrast the LHS design with those mentioned earlier in this report. It is first noted that the ratio of the number of runs to the number of inputs for the application of the LHS design is 200/7. This provides over 28 computer runs per input variable. If this ratio were maintained, then a computer code involving 200 inputs, for example, would require over 5,700 computer runs. Based on this example it is difficult to believe that LHS designs are recommended to select inputs for computer codes involving hundreds of variables. (5) In contrast, the main effects designs mentioned previously yield main effect information on $2^{k}-1$ variables with $2^{k}$ runs for a ratio of approximately 1 computer run per variable. The ratio differs from unity only because the mean response is computed and the mean is not counted as a main effect. Moreover, with main effects designs it is known exactly what effects and interactions are confounded. This knowledge permits future runs to be identified that will reduce or altogether eliminate unwanted confounding. Because the LHS designs yield random combinations of levels of the inputs, it is impossible to state in advance which effects will be confounded and which will not. Again, it seems unreasonable to make expensive computer runs using combinations of levels that are determined by chance. Extensive literature is available to permit an admittedly difficult, but rational, selection of experimental designs with known theoretical properties. (7) At the very least, it seems that if one were committed to using the LHS design, it would be prudent to 
make a careful examination of the combinations of levels that the randomization produced. If the results were not attractive relative to conventional designs, then the randomization procedure should be repeated in hopes of improving the properties of the design.

\subsubsection{Latin Hypercube Sampling and Sensitivity Analys is}

It should be noted that the primary use of the LHS design is to obtain an estimate of the output probability distribution; it is not asserted to yield directly the relative importance of the various inputs in determining the magnitude of the output. Instead, the results obtained from the LHS design are first examined to determine if each output is a monotone function of each input. If this is true, then the actual levers of each input and output variable are replaced by their ranks. As a result monotone relations are made linear. The technique of stepwise regression is then used to determine the relative importance of the input variables. Thus, it is next necessary to consider the validity of stepwise regression to determine relative importance of input variables.

To begin it is noted that software packages for stepwise regression generally use an F-ratio, or some variant of an F-ratio, to determine which variable at each step "explains" the largest portion of the residual variance that remains at that stage. The input variable having the largest F-ratio is identified as the next variable to enter the regression model. In this way the stepwise regression procedure identifies the importance of the variables: the most important variable is identified first, then the second most important variable is identified next, etc.

Unfortunately, this procedure is not free of difficulties. As an example of one of the difficulties consider the following. Suppose the levels for the most important variable are partitioned into relatively low levels and relatively high levels, say those below and above the median, for example. Now consider the problem of identifying the second most important input, given the condition that the first input has relatively low values. Suppose that this second most important input 
is found to be $\alpha_{5}$. Next, find the second most important input, given the condition that the first input has relatively high values. Suppose

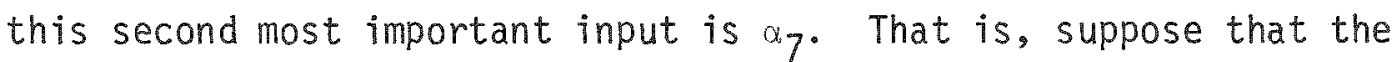
second most important input variable depends on the level of the first important variable. This is not a contrived rare instance of a data structure that is unlikely to occur in actual practice. In fact, a software package, known as the Automatic Interaction Detector (AID) program, identifies best inputs conditional on the levels of previous inputs. Many, if not most, real sets of data show different second best variables depending on the level of the best (first) variable. How does stepwise regression perform when used on such a data structure? First of all, stepwise regression can only provide a single "second best" variable. In the above hypothetical example, the stepwise regression procedure may show, for example, that $\alpha_{5}$ is second best, or that $\alpha_{7}$ is second best, or possibly that some other input variable is second best. In general, stepwise regression can only give one answer where two answers may be required. The variable identified as the second best variable may, in fact, be a poor choice over the high range of the first (best) variable. Stepwise regression is a smoothing (least-squares) procedure, and in selecting the best succession of inputs the procedure frequently fails because the structure of the data set is such that the second best variable is different depending on whether the first (best) variable is at a high or low level. On this basis, the use of stepwise regression to determine the relative importance of input variables is suspect, and may yield total misleading average information on the relative importance of the input variables.

In summary, the LHS design and the related techniques of rank transformations to achieve linearity, followed by stepwise regression to identify the relative importance of input variables, are found to be 1 imited to monotone relations, and even within that constraint, may well yield incorrect results. For these reasons, the Latin hypercube sampling method is not recommended for sensitivity analysis. When reduced experimental designs must be used, external evidence must first be obtained in order to identify which main effects and interactions are negligibly small. An experimental design should then be used that has confounding properties consistent with the identified negligibie effects. 


\section{ANALYTICAL APPROACHES TO UNCERTAINTY ANALYSIS}

This section of the report is primarily concerned with the adjoint method of sensitivity analysis. The method is first discussed in expository terms. Following this discussion, certain concepts related to total differentials and the statistical propagation of error are introduced, and finally a simple example of the adjoint method is developed in some detail.

\subsection{THE ADJOINT METHOD}

The adjoint method of sensitivity analysis is a technique that has received increasing development over the past decade. Most applications to date have been made in the areas of nuclear reactor physics. (8) (9) (10) The method is rigorous and has been shown to be applicable to a wide variety of systems of algebraic and differential equations, including linear and nonlinear systems. (11)(12) The mathematical origins of the method can be found in the calculus of variations (13), the theory of perturbations, and in inner-product spaces. (15)(16)

In general, the adjoint method exploits the fact that many mathematical systems of equations can be reformulated to give a different, but related, system of adjoint equations. The two sets of equations, primal and adjoint, are analogous to the primal and dual formulations of problems in linear programming. In making a sensitivity analysis both the primal system and the adjoint system of equations are solved. The solutions, in turn, are used as coefficients in the "adjoint sensitivity equation" to express the approximate numerical change in a "response function" to any single input, or to any combination of inputs.

With the possible exception of those in Reference (11), simple examples illustrating the adjoint method of sensitivity analysis have not been found in the published 7iterature. Sets of simultaneous 1 inear differential equations and eigenvalue problems can be used to illustrate the adjoint method. However, for this report these examples seem to be unnecessarily complex. Consequentiy, at the risk of oversimplification, 
a brain-teaser problem, known as the Cork and Bottle Problem, is used in the remainder of this report to illustrate the adjoint method of sensitivity analysis. Before presenting the problem, several concepts are discussed that relate to analytical methods of sensitivity analysis.

\subsubsection{The Total Differential}

Initial analytical approaches to uncertainty analysis are usually based on the total differential

$$
\widehat{d R}=\frac{\partial R}{\partial x_{1}^{0}} d x_{1}+\ldots+\frac{\partial R}{\partial x_{n}^{0}} d x_{n}
$$

associated with a continuous function

$$
R=R\left(x_{1}, \ldots, x_{n}\right),
$$

where the partial derivatives are assumed to exist and are evaluated at some fixed point $x^{0}$. Note that the partial derivatives are taken with respect to variables $\underline{x}$, not parameters. Thus, only a highly restricted form of uncertainty analysis can be associated with this form.

The substitution of numerical values for the finite increments dx into Equation (4) yields a numerical approximation to the change in the response function $\widehat{d R}$. The exact change $d R$, due to finite increments $d \underline{x}$, can be obtained only by solving the response function to permit a direct caiculation of the difference:

$$
\begin{aligned}
d R=R^{\prime}-R= & R^{\prime}\left(x_{1}+d x_{1}, \ldots, x_{n}+d x_{n}\right), \\
& -R\left(x_{1}, \ldots, x_{n}\right) .
\end{aligned}
$$

The usefulness of the approximate expression for $d R$ lies in the fact that the response equation need not be solved repeatediy in order to obtain an estimate of the effect of small changes in any single variable, or combination of the variables. It is clear that the approximation $\widehat{d R}$ given by Equation (4) improves and becomes exact as the finite increments $d \underline{x}$ approach zero. Conversely, the approximation is likely to degrade as the 
finite increments increase in magnitude. It should be noted that it may be difficult to determine the exact ranges of the increments that will yield acceptable approximations $\widehat{d R}$. Some experience indicates that parameter changes up to 30 percent give satisfactory approximations. (1)

\subsubsection{Propagation of Error}

A standard statistical development is frequently based on Equation (4). It is assumed that the $d x_{i}$ 's are random variables with expected values equal to 0 , and variances equal to $\sigma_{i}{ }^{2}$. The fixed point $x^{0}$ is taken to be the mean $\left(\bar{x}_{1}, \ldots, \bar{x}_{n}\right)$. Under these conditions the variance of $d R$ is found to be given by (17)

$$
\begin{aligned}
& \sigma_{d P .}^{2}=\left(\frac{\partial R}{\partial \bar{x}_{1}}\right)^{2} \sigma_{1}^{2}+\ldots+\left(\frac{R}{\partial \bar{x}_{n}}\right)^{2} \sigma_{n}^{2} \\
& +2\left(\frac{\partial R}{\partial \bar{x}_{1}}\right)\left(\frac{\partial R}{\partial \bar{x}_{2}}\right)_{1,2} \sigma_{1} \sigma_{2}+\ldots+2\left(\frac{\partial R}{\partial \bar{x}_{n-1}}\right)\left(\frac{\partial R}{\partial \bar{x}_{n}}\right)_{n-1, n{ }_{n-1} \sigma_{n}}
\end{aligned}
$$

where $\rho_{i, j}$ denotes the correlation between $d x_{i}$ and $d x_{j}$. This equation is frecuently used in analyses involving "propagation of error", especially when the $d x^{\prime}$ 's are taken to be uncorrelated. (18)

\subsubsection{Constrained Increments}

In the differential form of Equation (4) the increments $\mathrm{d} x{ }_{j}, \ldots$, $d x_{n}$ are considered to be independent so that values may be arbitrarily assigned to these increments. In many instances the increments cannot be arbitrarily assigned because they must satisfy some constraining equations. In such a case Equation (4) is of 7ittle use. As a simple example, suppose that $x_{1}$ and $x_{2}$ satisfy the equation

$$
a_{11} x_{1}+a_{12} x_{2}=b_{1}
$$

where $a_{11}, a_{12}$, and $b_{1}$ have fixed parameter values. Substituting $\left(x_{1}+d x_{1}\right)$ and $\left(x_{2}+d x_{2}\right)$ for $x_{1}$ and $x_{2}$, and simplifying yields

$$
a_{11} d x_{1}+a_{12} d x_{2}=0
$$


This relation shows that the assignment of any numerical value for $d x_{1}$ determines the value of $\mathrm{dx}_{2}$ and conversely. A different approach to approximating $d R$ is required when the $x$ 's, and therefore the $d x$ 's are required to be a solution to a given set of equations. In the modified approach, it is considered that the $x$ 's are best regarded as functions of the parameters of the given set of equations. A given set of numerical values for the parameters then yields a particular numerical solution for the $x$ 's. A change in the numerical value of any parameter is then associated with changes in one or more $x^{\prime} s$ which, in turn, results in a change in the numerical value of the response function. This chain of relations is illustrated by the example developed below.

\subsubsection{The Cork and Bottle Problem}

The cork and bottle problem can be used to illustrate the analytical approach and certain properties of the adjoint method of sensitivity analysis. This problem is a common "brain teaser" and usually takes the following form:

A cork and bottle cost 11 cents.

The bottle costs 10 cents more than the cork.

How much does the bottle cost?

The problem is formulated in a manner to lead the unwary to give the simple and incorrect answer that the bottle costs 10 cents and the cork costs 1 cent. This answer is incorrect because if the cork costs 1 cent and the bottle costs 10 cents more than the cork, then the bottle must cost 11 cents, but then the total cost is 12 cents, contradicting the first statement of the problem.

Letting $x_{7}$ and $x_{2}$ denote the costs of the bottle and the cork, respectively, an algebraic formulation of the problem takes the following form:

$$
\begin{array}{r}
x_{1}+x_{2}=11 \\
x_{1}-x_{2}=10 \\
R=x_{1}
\end{array}
$$


where the response $R$ denotes the cost of the bottle. The solution to these equations is seen to be given by $\left(x_{1}, x_{2}\right)=(101 / 2,1 / 2)$, so that the cost of the bottle is $101 / 2$ cents, and the cost of the cork is $1 / 2$ cent.

\subsubsection{Generalized Cork and Bottle Problem}

The cork and bottle problem can be expressed in the following generalized algebraic form:

$$
\begin{aligned}
& a_{11} x_{1}+a_{12} x_{2}=b_{1} \\
& a_{21} x_{1}-a_{22} x_{2}=b_{2}
\end{aligned}
$$

with a general response function given by

$$
R=c_{1} x_{1}+c_{2} x_{2}
$$

In words, the generalized cork and bottle problem becomes:

If $a_{11}$ bottles and $a_{12}$ corks cost $b_{1}$ cents,

and if $a_{21}$ bottles cost $b_{2}$ cents more than $a_{22}$ corks,

then how much do $c_{1}$ bottles and $c_{2}$ corks cost?

In this form the cork and bottle problem is seen to involve 8 parameters: $a_{17}, a_{12}, a_{27}, a_{22}, b_{1}, b_{2}, c_{1}$, and $c_{2}$. In the following development we use the adjoint method to quantify the sensitivity of the response function to these parameters.

We begin by supposing that each parameter (except $c_{2}$ ) is changed by \pm 10 percent from the nominal value given in Equation (6). (The parameter $c_{2}$ is omitted because it is equal to zero in Equation (6).) This gives 3 levels for each of 7 input parameters for a total of $3^{7}=2,187$ different combinations of changes in the input parameters. These changes yield an equal number of changes in the response function. Said another way, the cork and bottle problem would have to be solved 2,187 times in order to obtain the exact change in the response function for each set 
of parameter variations. It is shown below that all of the changes in the response function can be estimated by numerical substitutions into a single algebraic adjoint sensitivity equation. The adjoint sensitivity equation requires that two problems to be solved: namely, the original cork and bottle problem and an "adjoint version" of this problem. Thus, 2 problems, not 2,187, must be solved to yield an approximate, but general, sensitivity equation that in turn permits virtually all sensitivity questions to be quantitatively answered.

As a preliminary to the general development, suppose that the coefficient $\mathrm{a}_{11}$ in the original cork and bottle problem is increased by 10 percent so that $a_{11}$ is increased from 1.0 to 1.1. (See Equations (6) and (7).) What is the approximate change in the cost of the bottle? In symbolic terms we seek the value of $\mathrm{dR} / \mathrm{da}_{11}$. When $\mathrm{a}_{11}$ is changed, the values of solution $x_{1}$ and $x_{2}$ change. These changes are represented by $\partial x_{1} / \partial a_{11}$ and $\partial x_{2} / \partial a_{11}$. When $x_{1}$ and $x_{2}$ change, the value of $R$ changes and these changes are represented by $\partial R / \partial x_{1}$ and $\partial R / \partial x_{2}$. The net effect of the change in $\mathrm{a}_{11}$ is then given by the estimate

$$
\frac{\widehat{d R}}{d a_{11}}=\frac{\partial R}{\partial x_{1}} \frac{\partial x_{1}}{\partial a_{11}}+\frac{\partial R}{\partial x_{2}} \frac{\partial x_{2}}{\partial a_{11}} .
$$

From Equation (6) it seen that $R=x_{1}$ so that $\partial R / \partial x_{1}=1$ and $\partial R / \partial x_{2}=0$ with the result that

$$
\widehat{d R}=\frac{\partial x_{1}}{\partial a_{11}} d a_{11}
$$

With $\mathrm{da}_{11}=0.1$ to correspond to a 10 percent increase it is seen that

$$
\widehat{d R}=(0.1) \frac{\partial x_{1}}{\partial \mathrm{a}_{11}} .
$$

Thus, the change in the response is determined except for the factor $\partial x_{7} / \partial a_{11}$. To complete the calculation it is necessary to find the change in $x_{1}$ that results from the 10 percent increase in $a_{17}$. The change in $x_{1}$ can be found, of course, by solving the set of cork and bottle equations with $a_{11}$ replaced by $1.1 a_{11}$. These equations are given by 


$$
\begin{array}{r}
1.1 x_{1}+x_{2}=11 \\
x_{1}-x_{2}=10
\end{array}
$$

The exact solution is easily found to be $\left(x_{1}^{1}, x_{2}^{1}\right)=(10,0)$ so that the new response is given by $R^{\prime}=x_{1}^{\prime}=10$ cents. The change in the response function due to the 10 percent increase in $a_{71}$ is then given by $d R=$ $R^{\prime}-R=10-10.5=-0.500$.

As shown later the following approximate expression for $d R$ is obtained using the adjoint method:

$$
\widehat{d R}=-x_{1} y_{1} d a_{11}
$$

where $y_{1}=0.5$ is obtained by solving the adjoint version of the cork and bottle problem. Substitution of $x_{7}=10.5, y_{7}=0.5$, and $d_{17}=0.1$ yields $\widehat{\mathrm{dR}}=-0.525$. The approximate adjoint estimate of $\mathrm{dR}$ is seen to be within 0.025 of the exact value of $d R$ when $a_{11}$ changes by 10 percent. More genera11y, Equation (8) shows that $\widehat{d R}=-5.25 \mathrm{da} \eta 1$ so that the approximate change in the response function is a linear function of $\mathrm{da}_{11}$. Thus, the approximate change in the response function due to a change in $a_{11}$ can be approximated for a range of values of $a_{11}$ without repeatedly solving Equation (6) for each value of a 11 . 


\subsection{PROCEDURE FOR MAKING AN ADJOINT SENSITIVITY ANALYSIS}

The following steps, based on Reference (11) are intended to describe the procedure required to apply the adjoint method of sensitivity analysis. The steps apply to the general form of the cork and bottle problem. The primal equations consist of a set of simultaneous linear equations of the form $A \underline{A}=\underline{b}$, together with a response function of the form $R=\underline{x} . \underline{c}$, where $A$ denotes a square matrix of coefficients, $\underline{x}$ denotes a vector of variables, $\underline{b}$ and $\underline{c}$ denote vectors of parameters, and the response function $R$ is a scalar product of the variable vector $\underline{x}$ and a parameter vector $\underline{c}$. More general sets of equations and response functions require more general mathematical procedures than those used below. However, it is believed that the general outline of the procedure holds in more general settings.

Table 1 shows the steps involved in making an adjoint sensitivity analysis. The first step simply establishes the fact that the primal problem has a numerical solution $\underline{x}$ and a corresponding value of the response function. The differentiation in step 2 yields two equations that involve $\partial x / \partial \alpha$. The adjoint relation shown in step 3 permits $\partial x / \partial \alpha$ to be eliminated from the differential of the response equation $\mathrm{dR} / \mathrm{d} \alpha$. This elimination yields the algebraic adjoint sensitivity equation, so that the sensitivity coefficients $(d R / R) /(d \alpha / \alpha)$ can be computed in step 4 . The numerical results can then be examined to identify which input parameters are the most sensitive in determining the magnitude of the response. Finally, other measures of uncertainty, such as variances $\sigma^{2}$, may be combined with the sensitivity coefficients to yield overall measures of uncertainty. These procedures are analogous to those used in the propagation of error. In this adjoint setting it would appear proper to refer to uncertainty analysis as the "propagation of parameter uncertainties to the response function." 
TABLE 1. PROCEDURE FOR MAKING A SENSITIVITY ANALYSIS USING THE ADJOINT METHOD (LINEAR CASE)

\begin{tabular}{|c|c|}
\hline Step & Procedure \\
\hline 1. & $\begin{array}{l}\text { Solve a consistent set of primal equations } \underline{A} \underline{x}=\underline{b} \text { for } \\
\underline{x} \text { and evaluate a response function } R=\underline{x} \cdot \underline{c} \text {. }\end{array}$ \\
\hline 2. & $\begin{array}{l}\text { Differentiate the primal equations and the response } \\
\text { function with respect to the generic parameter }\end{array}$ \\
\hline 3. & $\begin{array}{l}\text { Use the adjoint relation } y \cdot A \frac{\partial x}{\partial \cdot x}=\frac{\partial x}{\partial \alpha} \cdot A^{T} y \text { to } \\
\text { eliminate } \partial x / \partial a \text { from the differentiated response } \\
\text { function and thereby obtain the adjoint sensitivity } \\
\text { equation. }\end{array}$ \\
\hline 4. & $\begin{array}{l}\text { Use the adjoint sensitivity equation to generate a } \\
\text { table of sensitivity coefficients }(d R / R) /(d \alpha / \alpha) \\
\text { for each parameter } \alpha \text {. }\end{array}$ \\
\hline 5. & $\begin{array}{l}\text { Edit the numerical results to identify the inputs } \\
\text { that are the most important. }\end{array}$ \\
\hline 6. & $\begin{array}{l}\text { Combine the sensitivity coefficients with measures } \\
\text { of uncertainty to obtain overall measures of } \\
\text { uncertainty. }\end{array}$ \\
\hline
\end{tabular}




\subsubsection{Adjoint Sensitivity Equation for the Generalized Cork and Bott7e Problem}

The adjoint sensitivity equation for the generalized cork and bottle problem is given as follows:

$$
\begin{aligned}
\frac{d R}{d \alpha}= & x_{1} \frac{\partial c_{1}}{\partial \alpha}+x_{2} \frac{\partial c_{2}}{\partial \alpha}+y_{1}\left(\frac{\partial b_{1}}{\partial \alpha}-x_{1} \frac{\partial a_{11}}{\partial \alpha}-x_{2} \frac{\partial a 12}{\partial \alpha}\right) \\
& +y_{2}\left(\frac{\partial b_{2}}{\partial \alpha}-x_{1} \frac{\partial a_{21}}{\partial \alpha}-x_{2} \frac{\partial a_{22}}{\partial \alpha}\right)
\end{aligned}
$$

where $x_{1}$ and $x_{2}$ denote the solution to the original cork and bottle problem, $y_{1}$ and $y_{2}$ denote the solution to the adjoint equation given below, and $\alpha$ denotes a generic parameter value, meaning that $\alpha$ can be replaced by any one of the parameters $a_{17}, a_{12}, a_{21}, a_{22}, b_{7}, b_{2}, c_{7}$, or $c_{2}$.

Table 2 shows an outline of the derviation of Equation (9). The equation is shown in vector form at line 10 for the linear case; a more general version for a nonlinear problem is also given in the table. These derivations are based on those given in Reference (11). As indicated by the equation at line 6 of Table 2 the adjoint equation for the linear cork and bottle problem is given by $A^{\top} \underline{y}=c$, where $A^{\top}$ denotes the transpose of the matrix A. From Equation (7) these adjoint equations are seen to have the following form:

$$
\begin{aligned}
& a_{11} y_{1}+a_{21} y_{2}=c_{1} \\
& a_{12} y_{1}-a_{22} y_{2}=c_{2}
\end{aligned}
$$

The solution to these adjoint equations $\left(y_{7}, y_{2}\right)$, together with the solutions of the primal problem $\left(x_{1}, x_{2}\right)$, are all that is required to make computational use of Equation (9).

\subsubsection{Complete Sensitivity Analysis for the Cork and Bottle Problem}

The sensitivity analysis of the cork and bottle problem can now be completed. As before we begin by solving Equation (6): 
TABLE 2. DERIVATIONS OF ADJOINT

SENSITIVITY EQUATIONS

\begin{tabular}{|c|c|c|c|}
\hline Line & Linear Case & Nonlinear Case & Comment \\
\hline 1 & $A \underline{x}=\underline{b}$ & $g_{n}(\underline{x}, \underline{b})=0$ & $\begin{array}{l}\text { Solve primal problem } \\
\text { for } \underline{x} \text {. }\end{array}$ \\
\hline 2 & $R=\underline{c} \cdot \underline{x}$ & $R=R(\underline{x}, \underline{c})$ & $\begin{array}{l}\text { Evaluate response func- } \\
\text { tion. }\end{array}$ \\
\hline 3 & $A \frac{\partial x}{\partial \alpha}+\frac{\partial A}{\partial \alpha} \underline{x}=\frac{\partial b}{\partial \alpha}$ & $G \frac{\partial x}{\partial \alpha}+\frac{\partial g}{\partial b} \frac{\partial b}{\partial \alpha}=0$ & $\begin{array}{l}\text { Differentiate primal } \\
\text { problem. }\end{array}$ \\
\hline 4 & $A \frac{\partial x}{\partial \alpha}=\frac{\partial b}{\partial \alpha}-\frac{\partial A}{\partial \alpha} \underline{x}$ & $G \frac{\partial x}{\partial \alpha}=-\frac{\partial g}{\partial b} \frac{\partial b}{\partial \alpha}$ & $\begin{array}{l}\text { Solve for term involving } \\
\partial x\end{array}$ \\
\hline 5 & $\frac{d R}{d \alpha}=\underline{x} \cdot \frac{\partial C}{\partial \alpha}+\frac{\partial x}{\partial \alpha} \cdot \underline{c}$ & $\frac{d R}{d \alpha}=\frac{\partial R}{\partial C} \cdot \frac{\partial C}{\partial \alpha}+\frac{\partial X}{\partial \alpha} \cdot \frac{\partial R}{\partial X}$ & $\begin{array}{l}\overline{\partial \alpha} \cdot \\
\text { Differentiate response } \\
\text { function. }\end{array}$ \\
\hline 6 & $A^{\top} \underline{y}=\underline{c}$ & $G^{T} \underline{y}=\frac{\partial R}{\partial x}$ & $\begin{array}{l}\text { Set up and solve adjoint } \\
\text { equation for } \underline{y} \text {. }\end{array}$ \\
\hline 7 & $\frac{d R}{d \alpha}=\underline{x} \cdot \frac{\partial c}{\partial \alpha}+\frac{\partial x}{\partial \alpha} \cdot A^{T} \underline{y}$ & $\frac{d R}{d \alpha}=\frac{\partial R}{\partial C} \cdot \frac{\partial C}{\partial \alpha}+\frac{\partial x}{\partial \alpha} \cdot G^{T} \underline{y}$ & Substitute (6) into (5). \\
\hline 8 & $\frac{\partial x}{\partial \alpha} \cdot A^{T} \underline{y}=\underline{y} \cdot A \frac{\partial x}{\partial \alpha}$ & $\frac{\partial x}{\partial \alpha} \cdot G^{T} \underline{y}=\underline{y} \cdot G \frac{\partial x}{\partial \alpha}$ & $\begin{array}{l}\text { Set up adjoint trans- } \\
\text { formation. }\end{array}$ \\
\hline 9 & $\frac{d R}{d \alpha}=\underline{x} \cdot \frac{\partial C}{\partial \alpha}+\underline{y} \cdot A \frac{\partial x}{\partial \alpha}$ & $\frac{d R}{d \alpha}=\frac{\partial R}{\partial C} \cdot \frac{\partial C}{\partial \alpha}+\underline{y} \cdot G \frac{\partial x}{\partial \alpha}$ & Substitute (8) into (7). \\
\hline 10 & $\frac{d R}{d \alpha}=\underline{x} \cdot \frac{\partial C}{\partial \alpha}+\underline{y} \cdot\left(\frac{\partial b}{\partial \alpha}-\frac{\partial A}{\partial \alpha} \underline{x}\right)$ & $\frac{d R}{d \alpha}=\frac{\partial R}{\partial c} \cdot \frac{\partial c}{\partial \alpha}-\underline{y} \cdot\left(\frac{\partial g}{\partial b} \frac{\partial b}{\partial \alpha}\right)$ & $\begin{array}{l}\text { Substitute ( } 4 \text { ) into (9) } \\
\text { to get adjoint sensi- } \\
\text { tivity equation. }\end{array}$ \\
\hline
\end{tabular}

Source: Based on derivations in Reference (11). 


$$
\begin{array}{r}
x_{1}+x_{2}=11 \\
x_{1}-x_{2}=10 \\
R=x_{1}
\end{array}
$$

The solution is given by $\left(x_{1}, x_{2}\right)=(10.5,0.5)$ and the response $R$ equals 10.5 cents. We next form the adjoint equations, based on Equation (10), to get

$$
\begin{aligned}
& y_{1}+y_{2}=1 \\
& y_{1}-y_{2}=0 .
\end{aligned}
$$

These equations have the solution $\left(y_{1}, y_{2}\right)=(1 / 2,1 / 2)$. Equation (9), the adjoint sensitivity equation, is now given by

$$
\begin{aligned}
\frac{d R}{d \alpha}= & (10.5) \frac{\partial c_{1}}{\partial \alpha}+(0.5) \frac{\partial c_{2}}{\partial \alpha_{0}}+(0.5)\left(\frac{\partial b_{1}}{\partial \alpha_{\alpha}}-10.5 \frac{\partial a_{11}}{\partial \alpha}-0.5 \frac{\partial a_{12}}{\partial \alpha}\right) \\
& +(0.5)\left(\frac{\partial b_{2}}{\partial \alpha}-10.5 \frac{\partial a_{21}}{\partial \alpha}-0.5 \frac{\partial a_{22}}{\partial \alpha}\right)
\end{aligned}
$$

Next, we successively set a equal to the various parameters. Beginning with $a=c_{7}$, Equation (11) shows that $d R / d c_{7}=10.5$. This result may be transformed into a sensitivity coefficient by multiplying by $c_{7} / R$ to get $(d R / R) /\left(d c_{7} / c_{7}\right)=10.5 c_{7} / R$, and with $c_{7}=1, R=10.5$, it follows that the sensitivity coefficient for $c_{1}$ is equal to 1.0 .

Table 3 shows the results of computing the sensitivity coefficients for the cork and bottle parameters. The sensitivity coefficient for $c_{2}$ does not exist because $c_{2}$ is equal to zero in the primal cork and bottle problem. In terms of a ranking by absolute values, the response is decreasingly sensitive to the parameters in the following order: $c_{1}, b_{1}$, $a_{11}$ and $a_{27}, b_{2}, a_{12}$ and $a_{22}$. 
TABLE 3. SENSITIVITY COEFFICIENTS FOR THE CORK AND BOTTLE PROBLEM

\begin{tabular}{cr}
\hline $\begin{array}{c}\text { Input } \\
\text { Parameter, } \alpha\end{array}$ & $\begin{array}{r}\text { Sensitivity Coefficient, } \\
(\mathrm{dR} / \mathrm{R}) /(\mathrm{d} \alpha / \alpha)\end{array}$ \\
$c_{1}=1$ & $(0)^{*}=(0.00)$ \\
$c_{2}=0$ & $11 / 21=0.52$ \\
$b_{1}=11$ & $-1 / 2=-0.50$ \\
$a_{11}=1$ & $-1 / 42=-0.02$ \\
$a_{12}=1$ & $10 / 21=0.48$ \\
$b_{2}=10$ & $-1 / 2=-0.50$ \\
$a_{21}=1$ & $1 / 42=0.02$ \\
$a_{22}=-1$ & \\
\hline
\end{tabular}

*In strict terms the sensitivity coefficient for $c_{2}$ does not exist because $c_{2}$ is equal to zero in the primal cork and bottle problem. 
The results are shown graphically in the sketch below:

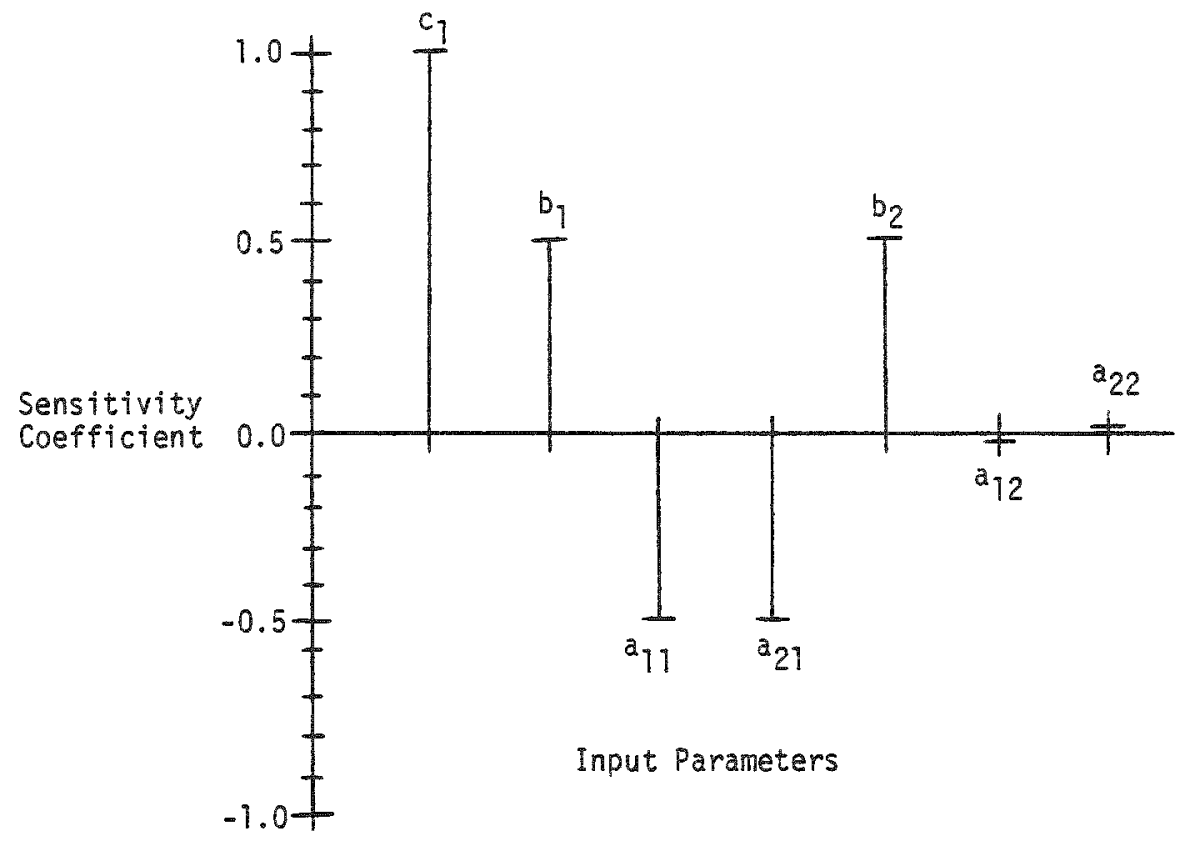

The sketch shows that changes in parameters $a_{12}$ and $a_{22}$ are relatively unimportant. The negative values for $a_{11}$ and $a_{21}$ show that percentage increases in these parameters are associated with percentage decreases in the response.

\subsection{ADDITIONAL RESULTS FOR THE LINEAR CASE}

In the course of evaluating the adjoint method of sensitivity analysis several practical results were obtained for the linear case. These resuits are reviewed in this portion of the report. In general, the results were obtained by attempting to make detailed comparisons between the number of computer runs required by the statistical sampling approach and by the analytical approach. 
3.3.1 Numerical Relations Among the Sensitivity Coefficients for the Linear Case

Some useful relations among the sensitivity coefficients can be obtained for the linear case. To obtain these relations we rewrite Equation (9) as follows:

$$
\begin{aligned}
\sum_{i=1}^{8}\left[\frac{d R_{i} / R}{d x_{i} / a_{i}}\right]= & \frac{x_{1} c_{1}}{R}+\frac{x_{2} c_{2}}{R}+y_{1}\left(\frac{b_{1}}{R}-x_{1} \frac{a_{11}}{R}-x_{2} \frac{a_{12}}{R}\right) \\
& +y_{2}\left(\frac{b_{2}}{R}-x_{1} \frac{a_{21}}{R}-x_{2} \frac{a_{22}}{R}\right) .
\end{aligned}
$$

The first two terms sum to unity because $x_{1} c_{1}+x_{2} c_{2}=R$. The terms contained in parentheses are equivalent to the primal equations and sum to zero. This shows that the sensitivity coefficients of the response sum to unity, and the sensitivity coefficients for each primal equation sum to zero. From this it follows that the sum of all the sensitivity coefficients is unity. The argument can clearly be extended to the general linear case.

As a numerical example consider the sensitivity coefficients for the cork and bottle problem shown in Table 3. The sensitivity coefficients for $c_{1}$ and $c_{2}$ sum to unity; those for $b_{1}, a_{11}$, and $a_{12}$ sum to zero; and those for $b_{2}, a_{27}$, and $a_{22}$ sum to zero. These relations can serve as a useful numerical check on the computed sensitivity coefficients for a linear primal problem.

\subsubsection{Computed Changes in Output Response}

The sensitivity coefficients can be used to obtain overall measures of uncertainty in the response as follows. Let $S_{i}$ denote a sensitivity coefficient so that

$$
S_{i}=\left(d R_{j} / R\right) /\left(d \alpha_{j} / \alpha_{j}\right), \quad i=1, \ldots, m_{0}
$$

where $d R_{i} / R$ is the fractional change in the response $R$ due to a fractional change $d \alpha_{j} / \alpha_{j}$. Then 


$$
d R_{j} / R=\left(S_{j} / \alpha_{j}\right) d \alpha_{j}, \quad i=1, \ldots, m,
$$

where $d \alpha_{j}$ denotes the uncertainty in parameter $\alpha_{j}$. The net percentage change in $R$ is given by the sum:

$$
d R / R=\sum_{i=1}^{m} d R_{i} / R=\sum_{i=1}^{m} s_{j}\left(d \alpha_{i} / \alpha_{i}\right) .
$$

Thus, the percentage uncertainty $d R / R$ in the response $R$ is seen to be a weighted combination of the percentage uncertainties $d a_{j} / \alpha_{i}$ in the input parameters $\alpha_{j}$. The weights are the sensitivity coefficients.

As an example the sensitivity coefficients given in Table 3 for the cork and bottle problem yield the following form:

$$
\begin{aligned}
\sum \frac{d R_{i}}{R}= & \left(\frac{d c_{1}}{c_{1}}\right)+\frac{11}{21}\left(\frac{d b_{1}}{b_{1}}\right)-\frac{1}{2}\left(\frac{d a_{11}}{a_{11}}\right)-\frac{1}{42}\left(\frac{d a_{12}}{a_{12}}\right) \\
& +\frac{10}{12}\left(\frac{d b_{2}}{b_{2}}\right)-\frac{1}{2}\left(\frac{d a_{21}}{a_{21}}\right)+\frac{1}{42}\left(\frac{d a_{22}}{a_{22}}\right)
\end{aligned}
$$

In this form it is clear that if each parameter is independently assigned $a \pm 10$ percent change, then $d \alpha / \alpha$ assumes three different values: $-0.1,0.0$, and 0.1 . With 7 parameters this yields $(3)^{7}=2,187$ different sensitivity calculations that can be made simply by substitution into Equation (12) to obtain the approximate fractional change in the response. The exact change in $R$ would require that the primal cork and bottle problem be solved 2,187 times. It is clear that Equation (12) is an extremely useful result even for such a simple problem as the cork and bottle problem. The power of the adjoint method is even more impressive when there are large numbers of input parameters. The corresponding equation for a generalized cork and bottle problem with 200 input parameters would yield an adjoint sensitivity equation with 200 terms, one for each $d \alpha / \alpha$, as in Equation (12). A plus and minus percentage change in each parameter would then yield $(3)^{200} \doteq 2.66 \times 10^{95}$ possible response calculations. In this case the sensitivity coefficients would be edited to retain only those that are relatively large. The sensitivity calculations might even be made on demand, whenever specific questions concerning the sensitivity of specific parameters arise. 


\subsubsection{Calculation of Main Effects}

Suppose that each input parameter $\alpha_{j}, i=1, \ldots, m$, is varied by $\pm p$ percent. The percent change in the response $d R / R$, due to such changes, is $\pm S_{j} p, i=1, \ldots, m$. The main effect of the change $d \alpha_{j} / \alpha_{j}$ on the response $d R / R$ is obtained as follows. Let $d R(t) / R$ denote the average response taken over 211 levels of 211 parameters other than $i$, given that $d \alpha_{j} / \alpha_{j}=p$. In computing the sum of the terms in $d R(+) / R$, the positive and negative contributions of all terms other than $i$ cancel out, with the result that $d R(+) / R=S_{i}\left(d \alpha_{j} / \alpha_{j}\right)$. In a similar manner, with $d R(-) / R$ denoting the average response taken over all levels of all parameters other than $i$, given that $d \alpha_{j} / \alpha_{i}=-p$, it follows that $d R(-) / R=-S_{j}\left(d \alpha_{j} / \alpha_{i}\right)$. The main effect of $d \alpha_{j} / \alpha_{j}$ is then given by the difference

$$
M\left(\alpha_{j}\right)=(d R(+) / R)-(d R(-) / R)
$$

and we find

$$
M\left(\alpha_{i}\right)=2 S_{i}\left(d \alpha_{j} / \alpha_{j}\right), \quad i=1, \ldots, m \text {. }
$$

Thus, the main effect of $\left(d \alpha_{j} / \alpha_{j}\right)$ on the output response $d R / R$ is proportional to $\left(d \alpha_{j} / \alpha_{j}\right)$ with a constant of proportionality equal to twice the sensitivity coefficient.

\subsubsection{Statistical Propagation of Uncertainty}

As suggested by Equation (12) the adjoint sensitivity equation can be used to identify "worst case" situations. These situations would result if all deviations in the input parameters occurred simultaneously, together with appropriate signs, to yield extreme positive or negative values for the total deviation in the output response. In many instances it would be important to be able to compute these extreme changes. On the other hand, it is also true that such extremes are not likely to occur 
by chance alone. That is, if the deviations among the input parameters are generally uncorrelated, then some deviations would likely "cancel out" other deviations, resulting in more moderate changes in the output response. The following statistical arguments can be used to obtain estimates of the moderate changes in outputs that are more likely to result from changes in inputs.

Suppose that the average uncertainty in each parameter is zero so that

$$
E\left\{d \alpha_{i}\right\}=0, \quad i=1, \ldots, m .
$$

Suppose that the variance in each parameter uncertainty is denoted by $\sigma_{i}^{2}$ so that

$$
E\left\{\left(d a_{j}\right)^{2}\right\}=\sigma_{i}^{2}, \quad i=1, \ldots, m \text {. }
$$

Finally let the covariance between pairs of uncertainties $d \alpha_{j}$ and $d \alpha_{j}$ be given by

$$
E\left\{\left(d \alpha_{j}\right)\left(d \alpha_{j}\right)\right\}=\rho_{i j} \sigma_{j} \sigma_{j}, \quad i \neq j
$$

where $\rho_{i j}$ denotes the correlation coefficient between $\mathrm{d} \alpha_{i}$ and $d \alpha_{j}$. It follows that the mean of the overall uncertainty in the response function is zero and the variance of the overall uncertainty in the response is given by

$$
\begin{aligned}
\sigma_{d R}^{2}= & \sum_{j=1}^{m}\left(R S_{i} / \alpha_{j}\right)^{2} \sigma_{i}^{2} \\
& +2 \sum_{\substack{i=1 \\
i \neq j}}^{m}\left(R S_{i} / \alpha_{j}\right)\left(R S_{j} / \alpha_{j}\right) \rho_{i j} \sigma_{i} \sigma_{j} .
\end{aligned}
$$

By comparison with Equation (5) it is seen that this result is similar to the usual propagation of error equation. In the propagation of error formula the evaluated partial derivatives, taken with respect to the 
variables, $\partial R / \partial \bar{x}_{j}$, are replaced in the above equation by the parameter sensitivity terms $\left(R S_{j} / \alpha_{j}\right)$.

As a numerical example consider the original cork and bottle problem in which the uncertainties in the parameters $d_{\alpha} ;$ are taken to be uncorrelated with zero means and variances equal to 0.01 . Using Equation (13), $R=10.5$, and the parameter values and sensitivity coefficients given in Table 3 it is found that

$$
\begin{aligned}
\sigma_{d R}^{2}= & R^{2} \sigma^{2}\left[\left(s_{C_{1}} / c_{1}\right)^{2}+\left(s_{b_{1}} / b_{1}\right)^{2}\right. \\
& \left.+\ldots+\left(s_{a_{22} / a_{22}}\right)^{2}\right] \\
= & (10.5)^{2}(0.01)\left[(1 / 1)^{2}+(1 / 21)^{2}+(1 / 2)^{2}\right. \\
& \left.+(1 / 42)^{2}+(1 / 21)^{2}+(1 / 2)^{2}+(1 / 42)^{2}\right] \\
= & 83 / 50=1.66
\end{aligned}
$$

\subsubsection{The Statistical Approach Revisited: \\ The Adjoint-Sampling Method}

Earlier in this report the main effects design is identified as requiring the minimum number of runs using the black-box statistical approach to sensitivity analysis. Such a design permits $\left(2^{2}-1\right)$ main effects to be estimated using $2^{k}$ runs. In the cork and bottle problem, for example, the main effects of the 7 parameters could be estimated by solving the problem 8 times. To be valid this approach requires that the parameters do not interact. Suppose this is true; then the adjoint sensitivity equation for the linear case can be used. From Equation (9) it is seen that

$$
d R / d b_{1}=y_{1}
$$

and

$$
\mathrm{dR} / \mathrm{db}_{2}=\mathrm{y}_{2} \cdot
$$


These equations show that if $b_{1}$ is increased by 1 unit, so that $d b_{1}=1$, then the resulting change in the response $d R$ is equal to $y_{1}$, an adjoint variable. Similarly, if $b_{2}$ is increased by 1 unit, then the change in the response is equal to $y_{2}$, the remaining adjoint variable. In other words, by making 3 runs, not 8 runs as required by the main effects design, the adjoint sensitivity equation can then be used to make a complete sensitivity analysis.

These observations can be generalized and summarized as follows. Suppose a primal problem consists of a consistent set of $n$ simultaneous equations in $n$ unknowns, $A \underline{x}=\underline{b}$, together with a response function $R=c \cdot x$. Then the adjoint sensitivity equation of Table 2 holds:

$$
\frac{d R}{d \alpha}=\underline{x} \cdot \frac{\partial C}{\partial \alpha}+y \cdot\left(\frac{\partial b}{\partial \alpha}-\frac{\partial A}{\partial \alpha} \underline{x}\right)
$$

To use this equation $\underline{x}$ and $\underline{y}$ must be numerically evaluated. In the adjoint approach $\underline{y}$ is obtained by formulating and solving the adjoint version of the original problem, so that $\underline{x}$ and $\underline{y}$ are obtained from 2 runs. In the "adjoint-sampling" approach $\underline{y}$ can be obtained by making $n$ runs, with successive b-values increased by 1 unit for each run. The adjoint-sampling approach then requires a total of $(n+1)$ runs in order to use the above sensitivity equation. In these terms the "efficiency" of the adjointsampling approach relative to the conventional adjoint approach is given by $2 /(n+1)$, the ratio of the number of runs required by the adjoint method to the number of runs required by the adjoint-sampling method.

\subsubsection{A cost Criterion for the Linear Case}

The preceding result may be used to derive a cost criterion for the linear case. The criterion indicates which method is less costly, the conventional adjoint method or the adjoint-sampling method.

Let $C_{S}$ and $C_{A}$ denote the programming costs for the primal and adjoint versions of a linear simulation program $A \underline{x}=\underline{b}$, involving $n$ equations. The total cost of obtaining the use of Equation (14), the adjoint 
sensitivity equation, by means of the adjoint-sampling approach is given by

$$
c_{S}+(n+1) c_{R}
$$

where $C_{R}$ denotes the cost of a single computer run. The corresponding cost for the adjoint method is given by

$$
C_{A}+2 C_{R}
$$

The conventional adjoint method will be less costly than the adjointsampling method whenever the following inequality holds:

$$
c_{A}+2 C_{R}<C_{S}+(n+1) C_{R}
$$

Equivalently, the conventional adjoint method will be less costly when the number of linear equations satisfies the following relation:

$$
n>1+\left(C_{A}-C_{S}\right) / C_{R}
$$

With the simplifying assumption that the cost of programming the adjoint version is twice that of the primal version, so that $C_{A}=2 C_{S}$, it follows that

$$
n>1+c_{S} / C_{R}
$$

Thus, under these assumptions the conventional adjoint method will be less costly than the adjoint-sampling method if the number of linear equations involved exceeds, approximately, the ratio of the cost of programming the primal problem to the cost of a computer run to obtain a solution to the primal problem.

As a numerical example, suppose the cost of writing the program is $\$ 100,000$, and the cost of making one run of the resulting program is $\$ 1,000$. If the number of the linear primal equations exceeds 101 , then the adjoint method will be less costly; otherwise the adjoint-sampling method requiring $(n+1)$ runs is less costly. 


\subsection{LINEAR PROGRAMMING SOLUTIONS \\ TO CORK AND BOTTLE PROBLEMS}

In a previous section it is shown that for the linear case the adjoint-sampling method can be used to obtain the solutions $\underline{x}$ and $\underline{y}$ required to make computational use of the adjoint sensitivity equation. With the adjoint-sampling method it is not necessary to set up and solve the adjoint equations. Instead the primal problem is resolved $n$ times, once for each primal equation. In this section we show that for the linear case, and with appropriate computer software for solving linear programing problems, it may even be unnecessary to make the $n$ additional runs associated with the adjoint-sampling method. There are two requirements for eliminating the $n$ additional runs: (1) the primal problem must be reformulated so that it involves variables that are non-negative, and (2) the linear programming software must produce the solutions to both the primal problem and the dual version of the primal problem. The reformulation in terms of non-negative variables is routine and is illustrated below for the cork and bottle problem. At least one computer package provides the solution of the primal and dual problem.

The usefulness of the linear programming solution to the generalized cork and bottle problem stems from the fact that some linear programming packages have been written to handle large numbers of variables. One software package, for example, has the following limits on problem size. No problem of more than 8,190 rows, 32,760 columns, 32,760 unique, nonzero elements or more than 2,045 nonzero elements in a column can be processed.(20)

Linear programming algorithms typically have the following form: maximize $\underline{c} \cdot \underline{x}$ subject to the constraints $\underline{A} \underline{x} \underline{\underline{b}}$ and $\underline{x} \geq \underline{0}$. To relate the structure of the linear programming problem to the cork and bottle problem we require that the $A$ matrix be an $n$ by $n$ square matrix of rank $n$ so that the primal problem has a unique solution. We also require the constraints to be equality constraints so that $A \underline{x}=\underline{b}$.

Linear programming algorithms are frequently implemented in two phases. In Phase I the algorithm simply determines whether or not the constraints have a non-negative solution. If such a solution if found, 
then the actual optimization procedures are carried out in Phase II. In the cork and bottle problem it is clear that Phase II is of little use because we have assumed that $\underline{x}$ is unique, so that $R=\underline{x} \cdot \underline{c}$ is uniquely determined and can be neither maximized nor minimized. Moreover, Phase I would appear to be of little use because we have assumed that the primal problem has a unique solution. Thus, we don't need a linear programming algorithm to verify this. However, some linear programming algorithms for determining the existence of feasible solutions, $\underline{x} \geq \underline{0}$, generate useful supplementary information.

Commonly used algorithms for Phase I start by introducing an artificial variable into each constraining equation. The resulting unit matrix can then be used as a starting basis for the linear programming simplex procedure. The process of finding the solution to the constraints then consists of driving the artificial basis vectors out of the system of equations by replacing them by legitimate basis vectors. When all of the artificial variables are driven out, then the resulting solution vector $\underline{x}$ is determined. Of interest in the present setting is the fact that the final values associated with the artificial variables are then equal to the values of the adjoint variables. That is, the values of the adjoint variables can be found as supplementary Phase I output from standard linear programming software.

\subsubsection{A Numerical Example}

The original cork and bottle problem has the following form:

$$
\begin{aligned}
\text { Find } R=x_{1} \\
\text { given that } x_{1}+x_{2}=11 \\
x_{1}-x_{2}=10
\end{aligned}
$$

An initial linear programming formulation of this problem is given as follows: 


$$
\begin{aligned}
\text { Minimize } R= & x_{1}+w x_{3}+w x_{4} \\
\text { subject to } & x_{1}+x_{2}+x_{3}=11 \\
& x_{1}-x_{2}+x_{4}=10
\end{aligned}
$$

where the $x$-values must be non-negative. It is seen that artificial variables $x_{3}$ and $x_{4}$ have been added to the response function. The artificial variables are associated with an arbitrarily large cost coefficient $w$ in the response function. The constraining equations can be written in terms of 5 column vectors $P_{0}, P_{1}, \ldots, P_{4}$ as follows:

$$
\begin{aligned}
& \begin{array}{lllll}
P_{1} & P_{2} & P_{3} & P_{4} & P_{0}
\end{array} \\
& x_{1}\left[\begin{array}{l}
1 \\
1
\end{array}\right]+x_{2}\left[\begin{array}{r}
1 \\
-1
\end{array}\right]+x_{3}\left[\begin{array}{l}
1 \\
0
\end{array}\right]+x_{4}\left[\begin{array}{l}
0 \\
1
\end{array}\right]=\left[\begin{array}{l}
11 \\
10
\end{array}\right] \text {. }
\end{aligned}
$$

It is clear that columns $P_{3}$ and $P_{4}$ provide a unit matrix for a starting basis to the problem. In particular a feasible solution is given by $x_{3}=11$ and $x_{4}=10$, with $x_{1}=x_{2}=0$, and the associated value of the response function is then given by $R=27 \mathrm{w}$. This response is undesirable for two reasons. It involves the artificial values $x_{3}$ and $x_{4}$ and is arbitrarily large because of the occurrence of $w$ in the response function. The simplex algorithm aims to replace the artificial basis vectors $P_{3}$ and $P_{4}$ by the legitimate vectors $P_{1}$ and $P_{2}$ and thereby eliminate $w$ from the response function.

We have previously found the solution of the cork and bottle problem to be given by $\left(x_{1}, x_{2}\right)=(10.5,0.5)$ so that the solution $x$ is nonnegative. For the generalized cork and bottle problem it may be desirable to allow the $x$-values to be negative as well as zero or positive. To permit this the linear programming formulation must be modified so that each $x$ variable is replaced by the difference between two non-negative variables. For the present example, we let $x_{1}=x_{1}^{1}-x_{1}^{\prime \prime}$ and let $x_{2}=x_{2}^{\prime}-x_{2}^{\prime \prime}$ where the primed variables are a 11 non-neaative. With these substitutions the cork and bottle problem takes the following form: 


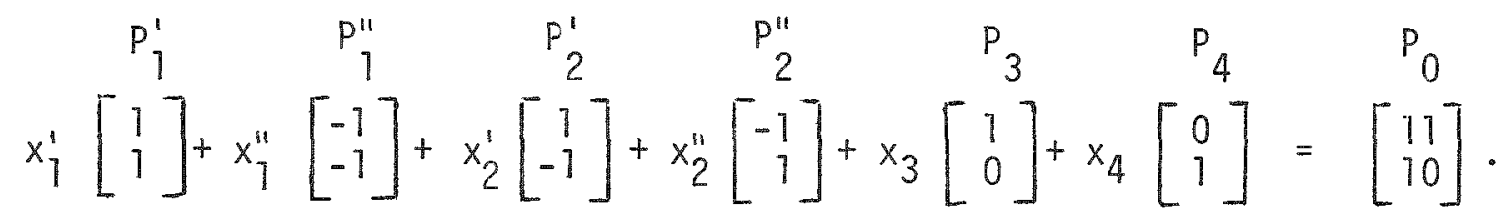

Because the column vectors for $P_{1}^{\prime}$ and $P_{1}^{\prime \prime}$, for example, are linearly dependent, they cannot both appear in the final basis; that is, $x_{1}^{\prime}$ and $x_{1}^{\prime \prime}$ cannot both be positive. This means that $x_{1}$ will ultimately be equal either to $x_{7}^{1}$ or $x_{7}^{11}$.

Finally, the response function is modified as follows:

$$
\text { Minimize } R=x_{1}^{\prime}-x_{1}^{\prime \prime}+w x_{3}+w x_{4} \text {. }
$$

This form reflects the fact that $x_{1}$ in the original response has been replaced by $x_{1}^{1}-x_{1}^{11}$ and that artificial variables having large cost coefficients $w$ have been added.

Table 4 shows the sequence of tableaus associated with the Tinear programming solution to the cork and bottle problem. The basis vectors and their associated costs are shown in lines 1 and 2 of columns 2 and 3 . The remaining columns in lines 1 and 2 show the P-vectors with the $P_{0}$-vector given first. Lines 3 and 4 show the $z_{j}-c_{j}$ calculations that govern the sequence in which the artificial vectors $P_{3}$ and $P_{4}$ are removed and replaced by legitimate vectors of the remaining columns.

The $z_{j}$-value is equal to the scalar product of the current cost vector and each of the $P$ vectors. In the first tableau, for example, the $z_{j}$ scalar products are given by

$\operatorname{cost} P_{0}$
$\left[\begin{array}{l}w \\ w\end{array}\right] \cdot\left\{\left[\begin{array}{l}11 \\ 10\end{array}\right],\left[\begin{array}{l}1 \\ 1\end{array}\right],\left[\begin{array}{l}-1 \\ -1\end{array}\right],\left[\begin{array}{r}1 \\ -1\end{array}\right],\left[\begin{array}{r}-1 \\ 1\end{array}\right],\left[\begin{array}{l}1 \\ 0\end{array}\right],\left[\begin{array}{l}0 \\ 1\end{array}\right]\right\}$

and are seen to be

$$
z_{j}=(2 T u, 2 w,-2 w, 0,0, w, w)
$$


TABLE 4. LINEAR PROGRAMMING SOLUTION TO THE CORK AND BOTTLE PROBLEM

INITIAL TABLEAU

\begin{tabular}{|c|c|c|c|c|c|c|c|c|c|}
\hline & & & 0 & 1 & -1 & 0 & 0 & $w$ & $w$ \\
\hline$i$ & Basis & Cost & $P_{0}$ & $\mathrm{P}_{i}$ & $P_{1}^{\prime \prime}$ & $P_{2}^{\prime}$ & $P_{2}^{\prime \prime}$ & $P_{3}$ & $P_{4}$ \\
\hline 1 & $P_{3}$ & $w$ & 11 & 1 & -1 & 1 & -1 & 1 & 0 \\
\hline 2 & $P_{4}$ & $w$ & 10 & (1) & -1 & -1 & 1 & 0 & 1 \\
\hline . & \multirow{2}{*}{\multicolumn{2}{|c|}{$\begin{array}{l}z_{j}-c_{j} \\
z_{i}-c_{i} \mid w\end{array}$}} & 0 & -1 & 1 & 0 & 0 & 0 & 0 \\
\hline 4 & & & 21 & 2 & -2 & 0 & 0 & 0 & 0 \\
\hline
\end{tabular}

SECOND TABLEAU

\begin{tabular}{llccccccccc}
\hline \hline & & 0 & $T$ & -1 & 0 & 0 & $w$ & $w$ \\
& Basis & Cost & $P_{0}$ & $P_{j}$ & $P_{1}^{\prime \prime}$ & $P_{2}^{\prime}$ & $P_{2}^{\prime \prime}$ & $P_{3}$ & $P_{4}$ \\
\hline 1 & $P_{3}$ & $w$ & 1 & 0 & 0 & 2 & -2 & 1 & -1 \\
2 & $P_{i}^{\prime}$ & 1 & 10 & 1 & -1 & -1 & 1 & 0 & 1 \\
\hline 3 & $z_{j}-c_{j}$ & 10 & 0 & 0 & -1 & 1 & 0 & 1 \\
4 & $z_{j}-c_{j} \mid w$ & 1 & 0 & 0 & 2 & -2 & 0 & -2 \\
\hline \hline
\end{tabular}

FINAL TABLEAU

\begin{tabular}{|c|c|c|c|c|c|c|c|c|c|}
\hline$i$ & Basis & $\cos t$ & $\begin{array}{l}0 \\
P_{0}\end{array}$ & $\begin{array}{l}1 \\
P_{i}\end{array}$ & $\begin{array}{l}-1 \\
P_{1}^{\prime \prime}\end{array}$ & $\begin{array}{l}0 \\
P_{2}^{\prime}\end{array}$ & $\begin{array}{l}0 \\
P_{2}^{\prime \prime}\end{array}$ & $\begin{array}{l}W \\
P_{3}\end{array}$ & $\begin{array}{l}w \\
P_{4}\end{array}$ \\
\hline 1 & $P_{2}^{\prime}$ & 0 & $1 / 2$ & 0 & 0 & 1 & -1 & $1 / 2$ & $-1 / 2$ \\
\hline 2 & $P_{i}^{\prime}$ & 1 & $101 / 2$ & 1 & -1 & 0 & 0 & $1 / 2$ & $1 / 2$ \\
\hline 3 & \multirow{2}{*}{\multicolumn{2}{|c|}{$\begin{array}{l}z_{j}-c_{j} \\
z_{j}-c_{i} \mid w\end{array}$}} & $101 / 2$ & 0 & 0 & 0 & 0 & $1 / 2$ & $1 / 2$ \\
\hline 4 & & & 0 & 0 & 0 & 0 & 0 & $-w$ & $-w$ \\
\hline
\end{tabular}


The corresponding $c_{j}$-values are given by the coefficients of the response function

$$
c_{j}=(0,1,-1,0,0, w, w),
$$

as shown above the P-vectors in the first row of each tableau. The difference between the vectors $\left(z_{j}-c_{j}\right)$ is then given by

$$
\left(z_{j}-c_{j}\right)=(21 w, 2 w-1,-2 w+1,0,0,0,0)
$$

It is convenient to split the components of this vector into those that involve $W^{\prime} s$ and those that don't; indicated as follows:

$$
z_{j}-c_{j}=(0,-7,1,0,0,0,0)
$$

and

$$
z_{j}-c_{j} \mid w=(21,2,-2,0,0,0,0)
$$

These are shown in lines 3 and 4 of the initial tableau.

The sequence of removing the artificial basis vectors is then determined by first identifying the largest positive element in the $z_{j}-c_{j} \mid w$ row among the vectors $P_{j}$ through $P_{4}$. The column corresponding to this element will enter the basis in the next tableau. For example, the element 2 is largest value for $P_{j}^{\prime}, \ldots, P_{4}$ in the initial tableau and indicates that $P_{j}^{\prime}$ will enter the next basis.

The determination of which vector will leave the current basis is made by examining, row by row, the ratios of the $P_{0}$ elements to the positive elements of the vector to be introduced into the basis. The row element corresponding to the minimum ratio is circled and is called the pivot element. The basis vector associated with the row containing the pivot element will be removed from the current basis. For example, in the initial tableau, the ratios of the $P_{0}$ elements to those of $P_{1}^{\prime}$ are given by $11 / 1$ and $10 / 1$. The minimum ratio is $10 / 1$, so the pivot element 
1 is circled. Basis vector $P_{4}$ will then leave the current basis and be replaced by vector $P_{j}^{\prime}$, as shown in the second tableau. The actual replacement is accomplished by adding suitable multiples of the pivot row to the remaining rows of the tableau in order to transform the incoming basis vector into a unit vector. In the initial tableau this is accomplished simply by subtracting row 2 from row 1 for vectors $P_{0}, \ldots, P_{4}$. The results are entered into the second tableau. The new basis vectors are indicated at the left of the new tableau, together with their cost coefficients, and the new $z_{j}-c_{j}$ values are computed as before. The procedure continues until all artificial vectors are removed from the initial basis.

The $P_{0}$ column in the final tableau shows that the solution to the cork and bottle problem is given by $x_{2}^{\prime}=x_{2}=1 / 2$ and $x_{1}^{\prime}=x_{1}=101 / 2$. In addition, in line 3 the $\left(z_{j}-c_{j}\right)$-values for the artificial variables $x_{3}$ and $x_{4}$ are shown to be $(1 / 2,1 / 2)$. These values are identical to the values of the adjoint variables $\left(y_{1}, y_{2}\right)$ found previously for the cork and bottle problem. Thus, the simplex procedure for removing the artificial vectors has generated the values of the adjoint variables.

The simplex procedure used in these hand calculations yields the values of the adjoint variables in the $\left(z_{j}-c_{j}\right)$ row of the final tableau. Different algorithms for linear programming yield these dual values in different ways, depending on whether the regular or revised simplex algorithm is used. If the revised algorithm is used, then it also depends on whether Standard Form I or Standard Form II is used. The details may be found in Reference (21), together with other relevant information concerning ties, degeneracy, etc. 


\section{CONCLUSIONS}

The analytical methods are found to be superior to the statistical sampling method in logical rigor and numerical accuracy. This finding stems primarily from the fact that analytical methods make direct use of the mathematical equations that are represented by the computer code. Among the analytical methods, the adjoint method is found to be particularly well-suited for obtaining the sensitivity coefficients for all input parameters, taken individually or in combination. With proper attention to coding procedures and with the use of currently developing software for obtaining partial derivatives (GRESS), the incremental costs for formulating and solving the adjoint version of the computer code can be minimized.

Among the statistical sampling methods, the Latin hypercube technique is found to be based on procedures that are generally unacceptable to classically trained statisticians. This stems directly from the use of random procedures to determine which combination of perturbed inputs should be run using the computer code. With the use of Latin hypercube sampling it is necessary to make rank transformations of the data, followed by stepwise regression, in order to obtain questionable sensitivity information on individual input parameters. Latin hypercube sampling is based on a sampling method that does not control the type or extent of confounding among main effects and interactions. As a result, the sampling is inferior to conventional experimental designs, such as fractional factorials and main-effect designs. The primary virtue of Latin hypercube sampling is the fact that it yields unbiased estimates of the probability density functions for computer outputs.

For the linear case it is found that a complete adjoint sensitivity analysis can be made without formulating, coding, and solving the adjoint version of the primal problem. This can be done in either of two ways. One method is based on a special type of statistical sampling, called adjoint-sampling in this report. The other method is based on transforming the primal problem into a linear programming problem. 


\section{RECOMMENDATIONS}

Based on the results of this task the following recommendations are made:

- ONWI should support the development and application of the adjoint method of sensitivity analysis.

- ONWI should not support the development of the Latin hypercube sampling method for sensitivity anaiysis. Limited use of the Latin hypercube sampling method may be justified for obtaining unbiased estimates of the probability density functions for computed outputs.

- ONWI should closely follow developments related to other analytical techniques for making sensitivity analyses.

- ONWI should rely as much as possible on conventional statistical procedures for quantifying the uncertainties of input parameters.

- ONWI should rely on conventional statistical designs, such as fractional factorials, for limited uncertainty analyses based on statistical sampling methods. External evidence should first be obtained in order to identify which main effects and interactions among the input parameters of the program are negligibly smal1. An experimental design should then be used with confounding properties that are consistent with the identified negligible effects. 


\section{LIST OF REFERENCES}

1. Frank, P. M., 1978. Introduction to Sensitivity Theory, Academic Press, New York.

2. National Bureau of Standards, 1959. Applied Mathematics Series, 54, U.S. Government Printing Office, Washington, D.C.

3. National Bureau of Standards, 1957. Applied Mathematics Series, 48, U.S. Government Printing Office, Washington, D.C.

4. Plackett, R. L., and J.P. Burman, 1943-1946. "The Design of Optimum Multifactorial Experiments", Biometrika, Vol.xxxiii, pp. 305-325.

5. Iman, R. L., and W. J. Conover, 1980. "Sma11 Sample Sensitivity Analys is Techniques for Computer Models, With an Application to Risk Assessment", Communications in Statistics, Theoretical Methods, Vol. A9(17), pp. 1749-1842.

6. Campbe17, J. E., R. L. Iman, and M. Reeves, 1980. Risk Methodology for Geologic Disposal of Radioactive Waste: Transport Model Sensitivity Analysis, NUREG/CR-1377, SAND80-0644, Sandia National Laboratories.

7. Natre11a, M. G., 1963. Experimental Statistics, National Bureau of Standards Handbook 91.

8. Weisbin, C. R., et a1, 1978. "Application of Sensitivity and Uncertainty Methodology to Fast Reactor Integral Experiment Analysis", Nuclear Science and Engineering, Vol. 66, pp. 307-333.

9. Oblow, E. M., 1978. "Sensitivity Theory for Reactor Thermal-Hydraulics Problems", Nuclear Science and Engineering, Vol. 68, pp. 322-337. 
10. Marable, J. H., C. R. Weisbin, and G. deSaussure, 1980. "Uncertainty in the Breeding Ratio of a Large Liquid-Metal Fast Breeder Reactor: Theory and Results", Nuclear Science and Engineering, Vo1. 75, pp. 30-55.

11. ObTow, E. M., 1978. "Sensitivity Theory for General Nonlinear Algebraic Equations with Constraints", Technical Note, Nuclear Science and Engineering, Vol. 65, pp. 187-191.

12. Cacuci, D. G., et 21, 1980. "Sensitivity Theory for General Systems of Nonlinear Equations", Nuclear Science and Engineering, Vol. 75, pp.88110.

13. Pomraning, G. G., 1967. "Variational Principle for Eigenvalue Problems", Journal of Mathematical Physics, Vol . 8, pp. 149-158.

14. Greenspan, E., 1980. "Perturbation Theory for Inertial Confinement Pellet Fusion Problems", Nuclear Science and Engineering, Vol. 74, pp. 185-192.

15. Lanczos, C., 1956. Applied Analysis, Prentice Hall, Inc., Englewood Cliffs, NJ.

16. Lipschutz, S., 1968. Theory and Problems of Linear Algebra, Schaums Outline Series, MCGraw-Hi11 Book Co., New York, NY, Chapter 13, pp. 279-313.

17. Hald, A., 1952. Statistical Theory with Engineering Applications, John Wiley \& Sons, Inc., New York, NY.

18. Beers, Y., 1957. Introduction to the Theory of Error, Addison-Wesley Publishing $C_{0}$., Inc., Reading, MA.

19. MPOS, 1978. Multi-Purpose Optimization System, Manual No. 320, Vogelback Computing Center, Northwestern University, Evanston, IL. 
20. Control Data Corporation, 1975. APEX-1II, Control Data Reference Manual, Minneapolis, MN.

21. Hadley, G., 1962. Linear Programming, Addison-Wesley Publishing Co., Reading, MA. 
$\therefore i$ 
APPENDIX A

\section{ALTERNATE DERIVATION OF THE ADJOINT SENSITIVITY EQUATION}

The following derivation of the adjoint sensitivity equation is based on material provided by Dr. Martin Becker, Rensselaer Polytechnic Institute.

Let a set of equations be expressed in operator form as follows:

$$
H_{\phi}-f=0 \text {, }
$$

where the operator $H$ incorporates difference approximation operations and coefficients. The external source term $f$ may correspond to a vector of radionuclides emanating from a repository, for example, and \& may correspond to a concentration of radionuclides in the ground as a function of position and time. Let a response function related to $\phi$ be defined as follows:

$$
J=-g^{T}
$$

where $\mathrm{g}^{\top}$ denotes the transpose of $\mathrm{g}$. The value of $\mathrm{J}$ may correspond to dose at a particular location and time. The vector $g$ would then contain the conversions from concentrations to dose multipled by the appropriate function of position. Because $H_{\phi} f=0$ the response function can be augmented by adding an arbitrary multiple of $\mathrm{H} \phi-f$ to obtain

$$
J=-g^{T} \phi+\phi^{* T}(H \phi-f)
$$

where the multiplying vector $\phi^{*}$ is not yet specified. Perturbations in $\checkmark$ yield the following result

$$
\begin{aligned}
\delta J= & -g^{T} \delta \phi+\delta \phi^{*}(H \phi-f) \\
& +\phi^{*}{ }^{T} \delta \phi+\phi^{*} \delta H \phi-\phi^{*} \delta f,
\end{aligned}
$$


where products of changes are neglected and $\delta g$ is taken equal to 0 . By means of the adjoint relation

$$
\phi * T_{H \delta \phi}=\delta \phi^{T} T_{H} T_{\phi}
$$

and

$$
g^{\top} \delta \phi=\delta \phi^{\top} g,
$$

it follows that

$$
\begin{aligned}
\delta J= & \delta \phi^{* \top}(H \phi-f)+\delta \phi^{\top}\left(H^{\top} \phi^{*}-g\right) \\
& -\phi^{*} \delta f+\phi^{*} \delta H_{\phi} .
\end{aligned}
$$

The first term vanishes because $H \phi-f=0$ and the second term can be made to vanish by choosing $\phi^{*}$ to be the solution of the adjoint equation:

$$
H_{\phi}^{\top}-g=0 .
$$

With this choice the perturbation of the response function is given by

$$
\delta J=-\phi^{*} \delta f+\phi^{*} \delta H \phi .
$$

This equation shows that effects of changes in the external source $\delta f$ and in the operator $\delta H$ on the response function. 


\section{DISTRIBUTION IIST}

ACRES AMERICAN INAC

A. S. BURGESS

ALABAMA DEPT OF ENERGY

CAMERON MCDONALD

ALLIS-CHALMERS

GARRICK J. SOLOVEY

AMERICAN FRIENDS SER VICE COMMITTEE WILLIAM REYNOLDS

ANALYSIS \& TECHNOLOGYINC

T. MAZOUR

ANALYTIC \& COMPUTATIONAL RESEARCH

INC

B. SAGAR

APPLIED MECHANICS INC JOHN R. WILLIAMS

ARGONNE NATIONAL LABORATORY WYMAN HARRISON

1. HOWARD KITTEL

C. J. ROBERTS

MARTIN I. STEINDLER

ARIZONA STATE UNIVERSITY

PAUL KNAUTH

BERNARD J. WOOD

ARTHUR D. LITTLE INC

AVIVA BRECHER

CHARLES R. HADLOCK

ATOMIC ENERGY CONTROL BOARD J. L. WALLACH

ATOMIC ENERGY OF CANADA LTD

M.O. LUKE

ANN QUINN

F. P. SARGENT

ATOMIC INDUSTRIAL FORUM INC

EMANUEL GORDON

AUSTRALIAN ATOMIC ENERGY COMMISSION

BABCOCK \& WILCOX

INFORMATION SERVICES

BAKER, TOUHILL, SHUCKROW \& ASSOCIATES INC

C.). TOUHILL

BATIELLE COLUMBUS DIVISION

JOHN T. MCGINNIS

JEFFREY L. MEANS

NEIL E. MILLER

STEPHEN NICOLOSI

THOMAS M. TRAINER

KENNETH R. YATES

BECHTEL GROUP INC

THOMAS S. BAER

DON B. CRANDALL

D. S. DUNCAN

N. A. NORMAN

MENDIX FIELD ENGINEERING CORP

BILL GRAHAM

CHARLES A. JONES

IOHN C. PACER

BHABHA ATOMIC TESEARCH CENTRE

V. SUKUMORAN

DLACK \& VEATCH

M. JOHN ROBINSON

ROEING ENGINEERING AND CONSTRUCTION COMPANY

R. B. CAIRNS

RRENK SYSTEMPLANUNC

H. D. BRENK

DRTISH NUCLEAR FUELS ITD

R.S. WILKS

BROOKHAVEN NATIONAL LAHORATORY

GERALD BIDA

M. S. DAVIS
SANDRAG LANE

P. W. LEVY

PETER SOO

HELEN TODOSOW (2)

MUNDESANSTALT FUR GEOWISSENSCHAFTEN

UND ROHSTOFFE

MICHAEL LANGER

HELMUT VENZLAFF

BUNDESMINISTERUMM FUR FORSCHUNG ROLF-PETER RANDL

DURNS AND ROE INDUSTRIAL SERVICES CORP JOHN PIRRO

C.R. WATTS ASSOCIATES CURTIS WATTS

CALIFORNIA DEPT OF CONSERVATION PERRY AMIMITO

CALIFORNIA DEPT OF HEALTH SERVICES BEVERLEE MYERS

CALIFORNIA INSTITUTE OF TECHNOLOGY LEON T. SILVER

CAMP, DRESSER, AND MCKEE INC WATER RESOURCES DIVISION

CANYONLANDS NATIONAL PARK PETER L. PARRY

CAPITAL AREA GROUND WATER

CONSERVATION COMMISSION A. N. TURCAN JR.

CASTUS VALLEY ORCHARDS CARL ANDERSON

CAYUGA LAKE CONSERVATION

ASSOCIATION INC

D.S. KIEFER

CENTRE D'INFORMATIQUE GEOLOGIQUE GHISLAIN DE MARSILY

CITIZENS ASSOCIATION FOR SOUND ENERGY IUANITA ELLIS

CITIZENS INSTITUTE FOR A POSITIVE ENERGY POLICY LINDSAY AUDIN

COLORADO GEOLOGICAL SURVEY JOHN W. ROLD

CONNECTICUT SITING COUNCI GLORIA DIBBLE POND

CONSERVATION COUNCIL OF NORTH

CAMOLNA

IANE SHARP

CONSOIL ASSOCIATES

DAVID A. LEE

COPPE/UFRI

LUIZ OLIVEIRA

CORNELL UNIVERSITY

JOHN BIRD

DUANE CHAPMAN

FRED H. KULHAWY

CORTLAND COUNTY MEALTH DEPT J. V. FEUSS

D. T.E.

KARL J. ANANIA

DALTON, DALTON \& NEWPORT

MARIA R. EIGERMAN

STEVE NACHT

DAMES \& MOORE

RON KEAR

CHARLES R. LEWIS

O.L. OZTUNOLI

DAPPOLONIA CONSULTING ENGINEERS INC

LISA K. DONOHUE

AMIRA HAMDY

JO JANET D. HOLCOMB

PETER C. KELSALL

CARLE. SCHUBERT
DAWCON MANAGEMENT CONSULTING

SERVICE

DAVID A. WEBSTER

DELAWARE CUSTOM MATERIEL INC HOWARD NOVITCH

DEPT OF THE ENVIRONMENT F.S. FEATES

DRAVO ENGINEERS AND CONSTRUCTORS KEN BEALL

DURE UNIVERSITY THOMAS DAVIS

E. DU PONT DE NEMOURS \& COMPANY DONALD E. GORDON

E.L.H. PUBLICATIONS - THE RADIOACTIVE

EXCHANGE

EDWARD L. HELMINSKI

E.R. JOHNSON ASSOCIATES INC E. R. $1 O H N S O N$

EARTH SCIENCE AND ENGINEERING INC LOU BLANCK

EARTH SCIENCES CONSULTANTS INC HARRY L. CROUSE

EAST TENNESSEE STATE UNIVERSITY MICHAEL R. SMITH

EBASCO SERVICES INC ZUBAIR SALEEM RAYMOND H. SHUM

ECOLOGY CENTER OF LOUISIANA ROSS VINCENT

EDISON ELECTRIC INSTITUTE R.E. L.STANFORD

EG \& G IDAHO INC RICHARD TALLMAN

ELECTRIC POWER RESEARCH INSTITUTE CHAIM BRAUN

ELECTROWATT ENGINEERING SERVICE H.N. PATAK

ELSAM

A. V. JOSHI

ARNE PEDERSEN

EMEASSY OF THE UNITED STATES MAUD LI HAIJLEN-RYLANDER

ENERGY FUELS NUCLEAR INC DON M. PILLMORE

ENERGY RESEARCH GROUP INC MARC GOLDSMITH

ENERGY RESEARCH LABORATORY MITACHI INC MAKOTO KIKUCHI

ENERGY, INC.

ENVIRONMENT CANADA CLAUDE BARRAUD

ENVIRONMENTAL POLICY INSTITUTE DAVID M. BERICK FRED MILLAR

ENVIRONMENTAL RESEARCH GROUP INC PETER G. COLLINS

ENVIROSPHERE COMPANY ROGER G. ANDERSON

ERIE COUNTY ENVIRONMENTAL

MANAGEMENT COUNCIL

IOAN P. SCHMIDT

EXXON NUCLEAR IDAHO COMPANY INC NATHAN A. CHIPMAN

D. L. CONDOTTA ROGER N. HENRY

EXXON PRODUCTION RESEARCH GARY WAYMIRE

F.B.A.B.

OTTO BROZEN 
T. M. MIKE E BRAZIE

FLORIDA DEPT OF ENVIRONMENTAL

REGULATION HAMITON OVEN

FLORIDA INSTTUTE OF TRCMNOLOGY IOSEPH A ANGELO, IR

FORD, MACON \& DAVIS UTAH INC PRESTONH HUNTER

FOSTER-MLLER ASSOCIATES INC NORBERT PAAS

FIEE UNIVERSTTAET MERIN HANSKARL. BRUEHL

FRIENDS OF THE EARTH LOUIS BUCKLIN

GERERAL ATOMIC COMPANY ROBERT M BURGOYNE ROBERT I CAMPANA H C CARNEY

GENEPAL COURT OF MASSACHUSETTS TIMOTHY I BURKE

GEO/RESOURCE CONSULTANTS INC ALVINK JOE, IR

GEORGTOWN CONSULTING GROUP SUSAN SHALAGAN

GEORGBA MNTITUTE OF TECHNOLOGY

MELVIN W CARTER

GEOFFREY G EICHHOLZ

ALFRED SCHNEIDER

CHARLESE WEAVER

GEOTECHNICAL ENGINEERS INC RICHARD W TURNBULL

GEOTHERMAL ENERGY INSTITUTE DONALDF $X$ FINN

GEOTRONS JAMES MERCER

GERAANTOWN FIENDS SCHOOL HERB BASSOW

GESELLSCHAFT F. STRAHLEN U

UMWETTOORSCHUNG M.B.H. HERMANN GIES

CIBPS \& HLL INC ROBERT PRIETO

GLORAL MARINE INC ROBERT F BAUER

GOLDER ASSOCIATES LAWRENCE A WHITE CLEMENT $M K$ YUEN

GTC GEOLOGIC TESTING CONSULTANTS LTD JOHN F PICKENS

H \& RT TECHNCAL ASSOCIATES INC WILLIAM R RHYNE

HAMN-MEITNER-INSTITUT FUR

KRENTORSCMUNG BERLIN KLAUS ECKART MAASS

HANFORD ENGINEERING DEVELOPMENT

LARORATORY

ALBERT G BLASEWITZ

R L KNECHT

HARDING LAWSON ASSOCIATES FRANK C KRESSE

HARVARD UNIVERSITY

DADE W MOELLER RAYMOND SIEVER

MDR SCIENCES DIVISION MARY 5 MORAN

MIRAM COLLGE IAMES W COWDEN

MOUGH-NORWOOD HEALTH CA GEORGEH BROWN, $M D$

LLLNOIS DEPT OF NUCLEAR SAFETY MILTON ZUKOR
ILLINOIS STATE GEOLOGICAL SURVEY KEROS CARTWRICHT

IMPEPIAL COLLEE OR SCIENCE ANO

TECHNOLOGY

B K ATKINSON

INDIANA UNIVERSITY

HAYDN H MURRAY

INSTITUT FUR TIEELAGERUNG

KLAUS KUHN

E R SOLTER

INSTITUTE FOR CHEMICAL TECHNOLOGY REINHARD ODO!

INSTITUTE OF GEOLOGICAL SCIENCES NEIL A CHAPMAN

INSTITUTE OF RADIAILON PROTECTION KAI JAKOBSSON

INTERA ENVIRONMENTAL CONSULTANTS INC F I PEARSON, JR ROBERT WILEMS

INTERNATIONAL ATOMIC ENERGY AGENCY EVERETT R IRISH

INTERNATIONAL ENGINEERING COMPANY

INC

MAX ZASLAWSKY

INTERNATIONAL RESEARCH AND

EVALUATION

$R$ DANFORD

IRT CORP

I STOKES

ISTITUTO SPERIMENTALE MODELLI

STRUTTURE S.P.A.

$F$ GERA

IACKSON STATE UNIVERSITY

ESTUS SMITH

IAPAN ATOMIC ENERGY RESEA IRCH INSTITUTE TARO ITO

IAY L. SMITH COMPANY INC JAYL SMITH

IFT AGAPITO \& ASSOCIATES INC MICHAEL P HARDY

IOHNS HOPKINS UNIVERSITY JARED L COHON

IOINT RESEARCH CENTRE GIRARDI FRANCESCO

IORDAN GORRILL ASSOCIATES IOHN D TEWHEY

KAISER ENGINEERS INC

W I DODSON

I S RITCHIE

KALAMAZOO COLLEGE RALPHM DEAL

KANSAS STATE GEOLOGICAL SURVEY WILLIAM W HAMBLETON

KTS LARS B NILSSON

KERNEORSCHUNGSZENTRUM KARLSRUHE GMBH

$K D$ CLOSS

KMHN ASSOCIATES

HARRY KIHN

KLOHN LEONOFE ITO

CRAIG FORSTER

SYOTO UNIVERSITY YORITERU INOUE

LANCASTER AVENUE URRARY FM CALVARESI

LAWRENCE BERELEY LABORATORY

NORMAN M EDELSTEIN

ORAH GOLDMAN

$\$$ KLAINER

ROBIN SPENCER

LAWRENCE UVERMORE NATIONAL

LABORATORY
LYNDEN B BALLOU

FRANCOIS E HEUZE

R CARROLL MANINGER

PAULL PHELPS

LAWRENCE D RAMSPOTT (2)

N SCHOCK

$W$ G SUTCLIFFE

TECHNICAL INFORMATION DEPARTMENT

$\lfloor-53$

RICHARD VAN KONYNENBURG

LERIGH UNEVERSITY

D R SIMPSON

LOS ALAMOS NATIONAL LABORATORY

GEORGE A COWAN

B CROWE

BRUCER ERDAL

WAYNE R HANSEN

CLAUDE HERRICK

DARLEANE C HOFFMAN

DONALDT OAKLEY

IOHN T WHETTEN

IOS ALAMOS TECHNICAL ASSOCIATES INC R J KINGSBURY

LOUUSIANA DEPT OF NATURAL RESOURCES B IIM PORTER

LOUISIANA DEPT OF TIAASPORTATION \&

DEVELOPMENT

GEORGEH CRAMER, II

IOUISIANA GEOLOGICAL SURVEY

CHARLES $\$$ GROAT

LEE W IENNINGS

LOUISIANA NUCLEAR ENERGY DIVISION

1 HALL BOHLINGER (3)

LOUISIANA TECH UNIVERSITY NORMAN WITRIAL

LOUISIANA TECHICAL NUCLEAR CENTER R H THOMPSON

LOWENSTEIN, NEWMAN, REIS \& AXELRAD

MICHAEL A BAUSER

MASSACHUSETTS INSTITUTE OF

TECHNOLOGY

WF BRACE

IOHN DEUTCH

RICHARD K LESTER

MCDERMOTI INC

KAREN 1 FURLOW

MECHANICAL TECHNOLOGV INC

STANLEY W DOROFF

MEMBERS OF THE GENERAL PUDLIC

W VON BLACK

DAVID H BOLTZ

IAMES BOYD

LARRY BRADLEY

WILLIAM E CONAWAY

WILLIAMV CONN

CLINTON I COONEY

D P DAUTOVICH

DANNELE DUDEK

FRANCES FARIEY

DOROTHY FORD

STEVE FRISHMAN

SHIRLEYM GIFFORD

KENNETH GUSCOTT

C F HAJEK

HAROLD L IAMES

KENNETH S IOHNSON

THOMASH LANGEVIN

GRANT W LAPIER

TERRY R LASH

DAVID LYLE

MAX MCDOWELL

IAMES B MUCKERHEIDE 
SHAILER S. PHILBRICK

JERRY SHEPPARD

PAUL SHEWMON

M. I. SZULINSKI

ROBERT WEESE

JIMMY L. WHITE

MICHIGAN DEPT OF PUBLIC HEALTH DON VAN FAROWE

MICHIGAN DISTRICT HEALTH DEPT NO 4 EDGAR KREFT

MICHIGAN GOVERNORS OFHICE WILLIAM C. TAYLOR

MICHIGAN LEGISLATIVE OFFICE OF SCIENCE ADVISOR

MINISTRY OF THE ENVIRONMENT IAAK VIIRLAND

MINNESOTA GEOLOGICAL SURVEY MATT S. WALTON

MISSISSIPPI ATTORNEY GENERALS OFFICE MACK CAMERON

MISSISSIPPI BUREAU OF GEOLOGY MICHAEL B.E. BOGRAD

MISSISSIPPI DEPT OF ENERGY AND

TRANSPORTATION JOHN W. GREEN (3)

MISSESSIPPI DEPT OF NATURAL RESOURCES CHARLES L. BLALOCK

MISSISSIPPI EMERGENCY MANAGEMENT

AGENCY

IAMESE. MAHER

MISSISSIPPI MINERAL RESOURCES INSTIYUTE

MISSISSIPPI STATE BOARD OF MEALTH

EDDIE S. FUENTE

1. WARREN CREEN

MISSISSIPPI SIATE HOUSE OF

MEPRIESENTATIVES

HILLMAN TEROME FRAZIER JERRY OKEEFE

MITRE CORP LESTER A. ETTLINGER

MITSUBISHI METAL CORP TATSUO ARIMA

MOBAY CHEMICAL CORP KENNETH H. HASHIMOTO

NASA JOHNSON SPACE CENTER MICHAEL R. HELFERT

NATIONAL ACADEMY OF SCIENCES JOHN T. HOLLOWAY PETER B. MYERS

NATIONAL AERONAUTICS AND SPACE

ADMINISTRATION - HEADQUARTERS PHILIP R. COMPTON

NATIONAL BOARD FOR SPENT NUCLEAR

FUEL, KARNBRANSLIENAMDEN NILS RYDELL

NATIONAL EUREAU OF STANDARDS RILEYM. CHUNG LEWIS H. GEVANTMAN WILLIAM P. REED

NATIONAL OCEANOGRAPHIC AND

ATMOSPHERIC ADMINISTRATION ALEXANDER MALAHOFF

NATIONALE GENOSSENSCHAFT FUR DIE

LAGERUNG RADROAKTIVER ABFALLE MARLIES KUHN

NATURAL RESOURCES DEFENSE COUNCIL THOMAS B. COCHRAN

NEVADA DEPT OF ENERGY ROBERT R. LOUX

NEW ENGLAND NUCLEAR CORP KERRY BENNERT
NEW JERSEY DEPT OF ENVIRONMENTAL PROTECTION

IEANETTE: BNG

NEW MEXICO ENVIRONMENTAL EVALUATION GROUP

ROBERT H. NEILL

NEW YORK DEPT OF HEALTH

DAVID AXELROD,M.D.

NEW YORK STATE ATTORNEY GENERALS

OFFICE

EZRA I. BIALIK

NEW YORK STATE ENERGY OPFICE IOHN P. SPATH (15)

NEW YORK STATE ERDA JOHN C. DEMPSEY

NEW YORK STATE GEOLOGICAL SURVEY ROBERT H. FAKUNDINY

NEW YORK STATE PUBLIC SERVICE

COMMISSION

FRED HAAG

NEYER, TISEO, \& HINDO LTD KAC R. HINDO

NORTH CAROLNA DEPT OF NATURAL

RESOURCES \& COMMUNITY DEVELOPMENT STEPHEN G. CONRAD

NORTH DAKOTA GEOLOGICAL SURVEY DON L. HALVORSON

NTR GOVERAMENT SERVICES THOMAS V. REYNOLDS

NUCIEAR ASSURANCE CORP ANDREW I. FRANKEL DAVID A. WEBSTER

NUCLEAR INFORMATION AND RESOURCE SEPVICE

GARY HZKOWITZ

NUCLEAR SAFETY ASSOCIATES INC IOSEPH A. LIEBERMAN

NUCLEAM SYSTEMS ASSOCIATES INC CHARLES I. DIVONA

NUCLEAR WASTE MANAGEMENT PROGRAM DONALD G. ANDERSON

NUCLEAR WASTE WATCHERS HELEN LETARTE

NUS CORP

W. G. BELTER

JOSEPH J. DINUNNO

BARRY N. NAFT DOUGLAS D. ORVIS

NWT CORP

W. L. PEARL

OAK RIDGE NATIONAL LABORATORY

J. O. BLOMEKE

H. C. CLAIBORNE

ALLEN C. CROFF

LESUIE R. DOLE

JOHN T. ENSMINGER

CATHYS. FORE

DAVID C. KOCHER

ELLEN D. SMITH

STEPHEN S. STOW

OFFICE OF NWTS INTEGRATION ROBERT E. HEINEMAN

OHIO STATE UNIVERSITY

R.N. CHRISTENSEN

A. T. CONLISK

M. A. CORNWELL

OKLAHOMA GEOLOGICAL SURVEY CHARLES I. MANKIN

OKLAHOMA STATE DEPT OF HEALTH R. L. CRAIG
ONTARIO RESEARCH FOUNDATION LYDIA M. LLCKEVICH

ORANGE COUNTY COMMUNITY COLLEGE LAWRENCE E. OBRIEN

OREGON DEPT OF ENERGY DONALD W. GODARD MICHAEL W. GRAINEY

OREGON STATE UNIVERSITY BRIAN DODD

U. C. RINGLE

ORGANIZATION FOR ECONOMIC

COOPERATION AND DEVELOPMENT J. P. OLIVIER

PACIFIC GAS AND ELECTRIC COMPANY RAYMOND L. BLUM

PACIFIC NORTHWEST LABORATORY

W. F. BONNER

DON I. BRADLEY

H. C. BURKHOLDER

L. L. CLARK

JOHN P. CORLEY

HARVEY DOVE

ORVILLEF. HILL

FLOYD N. HODGES

J. H. JARRETT

MAXR. KREITER

DONALD E. LARSON

ROBERT MCCALLUM

R. WILLIAM NELSON

R. E. NICHTINGALE

R. JEFF SERNE

R. E. WESTERMAN

PARSONS, BIINCKERHOFF, QUADE, \& DOUGLAS, INC

T. C. CHEN

T. R. KUESEL

PB-KBE INC

DILIPK. PAUL

MARK E. STEINER

PENBERTHY ELECTROMELT INTERNATIONAL INC.

LARRY PENBERTHY

PENNSYLVANIA GEOLOGICAL SURVEY

ARTHUR A. SOCOLOW

PENNSYLVANIA GOVERNORS ENERGY

COUNCIL

HERBER I IACOBS

PENNSYLVANIA STATE UNIVERSITY

MICHAEL GRUTZECK

WILLIAM A. JESTER

PERMIAN BASIN REGIONAL PLANNING COMMISSION

E.W. CRAWFORD

PERRY COUNTY BOARD OF SUPERVISORS

PALL D. JOHNSTON,SR

PERRY COUNTY CITIZENS AGAINST NUCLEAR

WASTE DISPOSAL

WARREN SIRICKLAND

PERRY COUNTY SCHOOLS

MANIEL A. COCHRAN

PHYSIKALSCH-TECHNISCHE RUNDESANSTALT PETER BRENNECKE

PORTLAND GENERAL ELECTRIC J. W. LENTSCH

POWER AUTHORITY OF THE STATE OF NEW YORK

MYRON M. KACZMARSKY

POWER REACTOR AND NUCLEAR FUEL

DEVELOPMENT CORPORATION

PRESQUE ISLE COURTHOUSE

PRINCETON UNIVERSITY

PETER MONTAGUE

G. F. PINDER 
PUBLIC SERVICE INDIANA ROBERT 5. WEGENG

RADIAN CORP BARBARA MAXEY

RADIATION PROTECTION COUNCIL TERI L. VIERIMA

RE/SPECINC PAUL F. GNIRK

RENSSELAER POLIYTECHNIC INSTITUTE IAMES WU

RICHTON CITY HALL R. RAHAIM

RIDIHALGH, EGGERS \& ASSOCIATES INC PHILIP E. EGGERS

RIO ALGOM CORP

DUANE MATLOCK

ROCKWELL HANFORD OPERATIONS

HARRY BABAD

G. S. BARNEY

R. A. DEJU

GEORGE C. EVANS (2)

L. R. FITCH

R. J. GIMERA

KUNSOO KIM

KARL M. LA RUE

ROCKWELL INTERNATIONAL

MICHAEL J. SMITH

K. THIRUMALAI

DAVE A. TURNER

ROCKWELL INTERNATIONAL ENERGV SYSTEMS

GROUP

HOWARD L. RECHT

LAWRENCE ! SMITH

ROGERS \& ASSOCIATES ENGINEERING CORP ARTHUR SUTHERLAND

ROGERS AND GOLDEN

IACK A. HALPERN

S.M. STOLLER CONP ROBERT W. KUPP

SANCANA INC

RALPH L. HOPKINS

SANDIA NATIONAL LABORATORIES

G. C. ALLEN

SHARLA BERTRAM

JOE A. FERNANDEZ

THOMASO. HUNTER

J. KEITH JOHNSTONE

R. L. LINK

R. W. LVNCH

MARTIN A. MOLECKE

IAMES T. NEAL

E. J. NOWAK

RICHARD E. PEPPING

G. F. RUDOLFO

SCOTT SINNOCK

A. W. SNYDER

A. E. STEPHENSON

LYNN D. TYLER

WIPP CENTRAL FILES

SAVANAAH RIVER LABORATORY

E. J. HENNELLY

CAROL JANTZEN

1. WENDELL MARINE

WILLIAM R. MCDONELL

JOHN A. STONE

S. V. TOPP

SCIENCE APPLICATIONS INC

RALPH FULLWOOD

RONALD HOFMANN

DAVID H. LESTER

JOHNE. MOSIER

HOWARD PRATT

M. D. VOEGELE
SENECA COUNTY PLANNING BOARD

SHAFER EXPLORATION COMPANY

WILLIAME. SHAFER

SIERTEA CLUR

EDNA ZEAVIN

SIERRA GEOPHYSICS INC

STEPHEN L. GILLETT

SIX-COUNTY COMMISSIONERS

ORGANIZATION

G. ALLEN FAWCETT

SNAKE RIVER ALIIANCE

TIM MCNEIL

SOUTH DAKOTA GEOLOGICAL SURVEY RICHARD BRETZ

SOUTHWEST RESEARCH AND INFORMATION

CENTER

DON HANCOCK

ALISON P. MONROE

STANFORD UNIVERSTTY

KONRAD B. KRAUSKOPF

IRWIN REMSON

STEARNS-ROGER SERVICES INC VERYL ESCHEN

STONE \& WERSTER ENGINEERING CORP J. PECK

EVERETT N. WASHER

SUMMIT COUNTY ENVIRONMENTAL SERVICES JAMES T. KING

SYSTEMS SCIENCE AND SOFTWARE PETER LAGUS

T.R.W.INC.

E. R. CHRISTIE

T.T.I. ENGINEERING CORP

DONALD C. TONIKA

TECHNICAL INFORMATION PROIECT DONALD PAY

TECHNICAL RESEARCH CENTIRE OF FINLAND SEPPO VUOR

TEKNEKRON RESEARCH INC ANTHONY F. MOSCATI

TERRA TEK INC

VICK BARTON

RICHARD LINGLE

TERRAMETRICS INC

HOWARD B. DUTRO

TEXAS A\&M UNIVERSITY

IOHNHANDIN

ROY W. HANN, JR.

GARY ROBBINS

JAMESE. RUSSELL

TEXAS ENERGY \& NATURAL RESOURCES

ADVISORY COUNCLL

TERRY BARRON

MILTON L. HOLLOWAY [5]

CAROL KING

TEXAS STATE REPRESENTATIVE PETE LANEY

THE ANALYTIC SCIENCES CORP

JOHN W. BARTLETT

CHARLES M. KOPLIK

THE CLARION-IEDGER

MARK SCHLEIFSTEIN

THOMSEN ASSOCIATES

C. T. GAYNOR, II

TRENDS PUBLISHING INC

TRW INC

PETER ALEXANDER

TVO POWER COMPANY VEIJO RYHANEN

U.H.D.E.

FRANK STEINBRUNN
U.K. DEPT. OF THE ENVIRONMENT

RADIOACTIVE WASTE MANAGEMENT DIVISION

U.S. ARMY CORPS OF ENGINEERS KATHARINE MATHER

U.S. IUREAU OF LAND MANAGEMENT

MARY PLUMB

EDWARD R. SCHERICK

GREGORY F. THAYN

U.S. WUREAU OF MINES

GEORGE E. NIEWIADOMSKI

U.S. DEPT OF COMMERCE

PETER A. RONA

U.S. DEPT OF ENERGY - ALBUQUERQUE

OPERATIONS OFFICE

R. LOWERY

JOSEPH M. MCGOUGH

DORNER T. SCHUELER

U.S. DEPT OF ENERGY - ASSISTANT GENERAL

COUNSEI FOR ENVIRONMENT

S. H. GREENLEIGH

U.S. DEPT OF ENERGY - CHICAGO

OPERATIONS OFFICE

D. BRAY

PAUL KEARNS

PUBLIC READING ROOM

R. SELBY

U.S. DEPT OF ENERGY - DALLAS SUPPORT

OFFICE

CURTIS E. CARLSON, JR.

U.S. DEPT OF ENERGY - HEADQUARTERS PUBLIC READING ROOM

U.S. DEPT OF ENERGY - IDAHO OPERATIONS OFFICE

JAMES F. LEONARD

PLBBLIC READING ROOM

J. H. SAKO

IOHN B. WHITSETT

U.S. DEPT OF ENERGY - MATERIALS SCIENCE DIVISION

R. J. GOTTSCHALL

U.S. DEPT OF ENERGY - NEVADA OPERATIONS OFFICE

I. B. COTTER

M.P. KUNICH

PUBLIC READING ROOM

U.S. DEPT OF ENERGY - NUCLEAR

ENVIRONMENTAL APPLICATION BRANCH ROBERT W. BARBER

U.S. DEPT OF ENERGY - NUCLEAR FUEL CYCLE

DIVISION

W. WADE BALLARD, JR.

U.S. DEPT OF ENERGY - NUCLEAR WASTE EDWARD F. MASTAL

U.S. DEPT OF ENERGY - NWTS PROGRAM OFFICE

T. BAILLIEUL

M. BLANCHARD

L. A. CASEY

MICHAEL T. PIELD

R. LAHOTI

L. K. MCCLAIN

1. O. NEFF

K. K.WU

R. C. WUNDERLICH

U.S. DEPT OF ENERGY - OAK RIDGE

OPERATIONS OFFICE

PUBLIC READING ROOM

U.S. DEPT OF ENERGY - OFFICE OF NUCLEAR

WASTE MANAGEMENT

EARL WAHLQUIST 
U.S. DEPT OF ENERGY - OFFICE OF PROIECT AND FACILITIES MANACEMENT

D I HARTMAN

U.S. DEPT OF ENEMGY - OFFICE OF WASTE

ISOLATION

I $W$ BENNETT

$C R$ COOLEY (2)

WARREN EISTER

C H GEORGE

JOSEPH A LEARY

THOMASP LONCO

JANIE SHAHEEN

I SMILEY

R STEIN

U.S. DEPT OF ENERGY - OFFICE OF WASTE

PRODUCTS

JAMES TURI

U.S. DEPT OF ENERGY - REGION IX

PUBLIC READING ROOM

U.S. DEPT OF ENERGY - RICHLAND

OPERATIONS OFFICE

R B GORANSON

PUBLIC READING ROOM

I SCHREIBER

U.S. DEPT OF ENERGY - SAN FRANCISCO

OPERATIONS OFFICE

LEN LANNI

U.S. DEPT OF ENERGY - SAVANNAH RIVER

OPERATIONS OFFICE

REGINAT HARRIS

$T$ B HINDMAN

U.S. DEPT OF ENERCY - WIPP PROGRAM LAWRENCE H HARMON

U.S. ENVIRONMENTAL PROTECTION AGENCY DIVISION OF CRITERIA \& STANDARDS DONALD HUNTER

IAMES NEIHEISEL

U.S. GEOLOGICAL SURVEY - COLUMBUS

A M LA SALA JR

U.S. GEOLOGICAL SURVEY - DENVER

M S BEDINGER

JESS M CLEVELAND

W SCOTT KEYS

U.S. GEOLOGICAL SURVEY - IACKSON

GARALD G PARKER IR

U.S. GEOLOGICAL SURVEY - MENLO PARK

JOHN BREDEHOEFT

$\int$ BYERLEE

JACOB RUBIN

U.S. GEOLOGICAL SURVEY - RESTON

I-MING CHOU

JOHN ROBERTSON

EUGENE H ROSEBOOM IR

PETER R STEVENS

DAVID B STEWART

U.S. HOUSE SUBCOMMITTEE ON ENERGY AND

THE ENYIRONMENT

MORRISK UDALL

U.S. NUCLEAR RECULATORY COMMISSION

J CALVIN BELOTE

R BOYLE

PATRICIA A COMELLA

ENRICO F CONTI

MICHAEL C CULLINGFORD

I) DAVIS

IOSEPH F DONOCHUE

$F \perp$ DOYLE

FREDERICK FORSCHER

RICHARD F FOSTER

PAULF COLDBERC

HIGH-LEVEL WASTE LICENSINC BRANCH

RALPH I JONES

PHILIP S JUSTLS

LINDA L LEHMAN

LIBRARY

JAMESC MALARO

IOHN B MARTIN (3)
IOHN C MCKINLEY

HUBERT MILLER

THOMAS I NICKOLSON

EDWARD ODONNELL

EVERETT A WICK

U.S. NUCLEAR REGULATORY COMMISSSION HICH-LEVEL WASTE TECHNICAL.

U.S. SENATE COMMITTEE ON ENERGY AND

NATURAL RESOURCES WILLIS D SMITH

U.W. - MILWAUKEE SARUP IYANE B IUDD

UHDE GMBH OLINGER

UNC NUCLEAR INDUSTRIES ED POWERS

UNION OF CONCERNED SCIENTISTS MICHAEL FADEN

UNIVERSITY OF ALEERTA FW SCHWARTZ

UNIVERSITY OF ARIZONA

IAAK DAEMEN

JAMES G MCCRAY

SHLOMO P NEUMAN

DAVID L SOUTH

UNIYERSITY OF CALIFORNIA AT BERKELEY TODD LAPORTE

UNIVERSITY OF CALIFORNIA AT LOS ANGELES D OKRENT

UNIVERSITY OF CALIFORNIA AT RIVERSIDE LEWIS COHEN

UNIVERSITY OF CINCINNATI ATTILA KILINC

UNIVERSITY OF DELAWARE

FRANK A KLLACKI

UNIVERSITY OF FIORIDA

DAVIDE CLARK

MIOHANIAN

UNIVERSITY OF HAWAII AT MANOA MURLI H MANGHNANI

UNIVERSTY OF ILLINOIS AT URBANA -

CHAMPAIGN

ALBERT I MACHIELS

MAGDI RAGHEB

UNIVERSITY OF LOWELL

JAMES R SHEFF

UNIVERSITY OF LULEA

IAN NILSSON

UNVERSITY OF MARYLAND

MARVIN ROUSH

UNIVERSTTY OF MINNESOTA

RAYMOND STERLING

IK TYLKO

UNIVERSTIY OF MISSOUII AT KANSAS CITY EDWIN D GOEBEL SYEDE HASAN

UNIVERSTYY OF MISSOURI AT ROLLA ALLEN W HATHEWAY

UNIVERSITY OF MODERA $M$ ANTONINI

UNIVERSITY OF NEVADA AT RENO RODNEY | WEICK

UNIVERSITY OF NEW MEXICO DOUGLAS G BROOKINS

UNIVERSITY OF NORTH CAROLINA PAUL D FULLAGAR

UNIVERSITY OF OKLAHOMA DANIEL T BOATRIGHT

UNIVERSITY OF PITTSBURCH $B$ L COHEN

UNIVERSITY OF RHODE ISLAND EDWARD P LAINE

UNIVERSITY OF SOUTHERN MISSISSIPPI CHARLES R BRENT

DANIEL A SUNDEEN

GARY L WILOMAN
UNIVERSTTY OF TEXAS AT AUSTIN

BUREALI OF ECONOMIC GLOIOGY

THOMAS C GUSTAVSON

DALE KLEIN

IOE D LEDBETTER

UNIVERSITY OF TEXAS AT SAN ANTONIO DONALD R LEMIS

UNIVERSITY OF TOKYO RYOMEI KIYOSE

UNIVERSITY OF TORONTO R M STESKY

UNIVERSITY OF WASHINGTON

DAVID BODANSKY

KAIN LEE

M A ROBKIN

UNIVERSITY OF WISCONSIN

B C HAIMSON

UNIVERSITY OF WISCONSIN AT MLWAUKEE HOWARD PINCUS

URS/JOHN A. BLUME \& ASSOCIATES, ENGINEERS

ANOREW B CUNNINGHAM

UTAH PUREAU OF RADIATION CONTROI DARRELL $M$ WARREN

UTAH SOUTHEASTERN DISTRICT HEALTH

DEFARTMENT ROBERT L FURLOW

UTAH STATE UNIVERSITY DEPT OF GEOLOGY

UTILITY DATA INSTITUTE FRED YOST

VANDERBLIT UNIVERSITY FRANK L PARKER

VERMONT AGENCY OF ENVIRONMENTAL

CONSERVATION

CHARLES A RATTE

VERMONT STATE NUCLEAR ADVISORY PANEL VIRGINIA CALLAN

VIRGINIA DEPT OF MEALTH ROBERT C WICKLINE

VIRGINAA MILITARY INSTITUTE HENRY D SCHREIBER

VIRGINIA POLYTECHNIC INSTITUTE AND

STATE UNIVERSITY

WALTER HIBBARD

WASHINGTON DEPT OF SOCIAL AND HEALTH SERVICES

T STRONC

WASHINGTON HOUSE OF REPRESENTATIVES RAYISAACSOR

WEST VALLEY NUCLEAR SERVICES COMPANY INC

RICHARD M WINAR

WESTINGHOUSE ELECTIIC CORP

CAROL A KIZIS

D NEWBY

GEORGE P SABOL

JAMESH SALING

WESTINGHOUSE WIPP PROIECT

WESIINGHOUSE ELECTRIC CORPORATION

WISCONSIN DEPT OF LOCAL AFFAIRS AND

DEVELOPMENT

DAVID WOODBURY

WISCONSIN GEOLOGICAL AND NATURAL

MISTORY SURVEY

MICHAEL G MUDREY, IR

MEREDITH E OSTROM

WOODS ROBELTSON ASSOCIATES

WOODWARD-CIYDE CONSULTANTS

F R CONWELL (2)

ASHOK PATWARDHAM

WP-SYSTEM AB

IVAR SACEFORS

WYOMING GEOLOGICAL SURVEY

DANIEL N MILLER 